\title{
Competition-based screening helps to secure the evolutionary stability of a defensive microbiome
}

Sarah F. Worsley ${ }^{1}$, Tabitha M. Innocent ${ }^{2 \dagger}$, Neil A. Holmes ${ }^{1,3+}{ }^{+}$, Mahmoud M. Al-Bassam ${ }^{1}$, Morten Schiøtt ${ }^{2}$, Barrie Wilkinson ${ }^{3}$, J. Colin Murrell ${ }^{4}$, Jacobus J. Boomsma ${ }^{2^{*}}$, Douglas W. Yu ${ }^{1,5,6^{*}}$ and Matthew I. Hutchings $s^{1,3^{*}}$ (D)

\begin{abstract}
Background: The cuticular microbiomes of Acromyrmex leaf-cutting ants pose a conundrum in microbiome biology because they are freely colonisable, and yet the prevalence of the vertically transmitted bacteria Pseudonocardia, which contributes to the control of Escovopsis fungus garden disease, is never compromised by the secondary acquisition of other bacterial strains. Game theory suggests that competition-based screening can allow the selective recruitment of antibiotic-producing bacteria from the environment, by providing abundant resources to foment interference competition between bacterial species and by using Pseudonocardia to bias the outcome of competition in favour of antibiotic producers.
\end{abstract}

Results: Here, we use RNA-stable isotope probing (RNA-SIP) to confirm that Acromyrmex ants can maintain a range of microbial symbionts on their cuticle by supplying public resources. We then used RNA sequencing, bioassays, and competition experiments to show that vertically transmitted Pseudonocardia strains produce antibacterials that differentially reduce the growth rates of other microbes, ultimately biassing the bacterial competition to allow the selective establishment of secondary antibiotic-producing strains while excluding non-antibiotic-producing strains that would parasitise the symbiosis.

Conclusions: Our findings are consistent with the hypothesis that competition-based screening is a plausible mechanism for maintaining the integrity of the co-adapted mutualism between the leaf-cutting ant farming symbiosis and its defensive microbiome. Our results have broader implications for explaining the stability of other complex symbioses involving horizontal acquisition.

Keywords: Antibiotics, Attini, Game theory, Defensive microbiome, Mutualism, Actinobacteria, Partner, Leaf-cutting ants, Pseudonocardia, Interference competition, Horizontal acquisition, Symbiosis

\footnotetext{
*Correspondence: jjboomsma@bio.ku.dk; douglas.yu@uea.ac.uk;

matt.hutchings@jic.ac.uk

†Tabitha M. Innocent and Neil A. Holmes contributed equally to this work.

${ }^{2}$ Centre for Social Evolution, Section for Ecology and Evolution, Department

of Biology, University of Copenhagen, Copenhagen, Denmark

${ }^{1}$ School of Biological Sciences, Norwich Research Park, University of East

Anglia, Norwich, Norfolk NR4 7TJ, UK

Full list of author information is available at the end of the article
}

\section{$\triangle B M C$}

(c) The Author(s). 2021 Open Access This article is licensed under a Creative Commons Attribution 4.0 International License, which permits use, sharing, adaptation, distribution and reproduction in any medium or format, as long as you give appropriate credit to the original author(s) and the source, provide a link to the Creative Commons licence, and indicate if changes were made. The images or other third party material in this article are included in the article's Creative Commons licence, unless indicated otherwise in a credit line to the material. If material is not included in the article's Creative Commons licence and your intended use is not permitted by statutory regulation or exceeds the permitted use, you will need to obtain permission directly from the copyright holder. To view a copy of this licence, visit http://creativecommons.org/licenses/by/4.0/ The Creative Commons Public Domain Dedication waiver (http://creativecommons.org/publicdomain/zero/1.0/) applies to the data made available in this article, unless otherwise stated in a credit line to the data. 


\section{Background}

The diversity of insect-associated microbial communities is staggering. They may consist of single intracellular symbionts with reduced genomes owing to coadaptation at one extreme [1] and to dynamic microbiomes in open host compartments such as guts at the other end of the scale [2]. Insect microbiomes have been intensively studied across a range of species, and there is increasing consensus regarding their vital contributions to host fitness throughout ontogenetic development [3-6]. However, the stability and cooperative characteristics of complex microbiomes are a paradox. While relentless competition is the default setting of the microbial world [7], hosts appear to evolve control by holding their microbiome ecosystems on a leash [8], but how dynamic stability under continuing turnover is achieved remains unclear. Despite an abundance of microbiome research, recent reviews have concluded that "integration between theory and experiments is a crucial 'missing link' in current microbial ecology" [9] and that 'our ability to make predictions about these dynamic, highly complex communities is limited' [10].

Game theory suggests a compelling solution to the unity-in-diversity paradox by showing that competitionbased screening can be a powerful mechanism to maintain cooperative stability. Screening is likely to work when hosts evolve (1) to provide nutrients and/or space to foment competition amongst symbionts, thus creating an attractive but 'demanding' environment, and (2) to skew the resulting competition such that mutualistic symbionts enjoy a competitive advantage. Competitive exclusion then 'screens in' mutualists and 'screens out' parasitic and free-rider symbionts [11-13]. Screening is conceptually clearest when the symbiont trait that confers competitive superiority is the same as (or strongly correlated with) the trait that benefits the host. An illustration of such correlated functionality was provided by Heil [14] who showed that ant-hosting acacia plants provide copious food bodies, which fuels the production of numerous, actively patrolling ant workers. The ant species whose colony invests in greater numbers of aggressive workers outcompetes other ant colonies trying to establish on the same plant, and the same investment in aggressive workers is likely to better protect the host plants against herbivores [14].

Screening has also been suggested to act in animalmicrobe symbioses. For instance, Tragust et al. [15] showed that carpenter ants acidify their own stomachs by swallowing acidopore secretions. Entomopathogenic bacteria are then rapidly killed off, whereas the coadapted gut bacterial symbiont Asaia sp. (Acetobacteraceae) exhibits a lower mortality rate and maintains itself in the midgut. Addressing a similar question, Itoh et al. [16] used co-inoculation experiments to show that environmentally recruited but co-adapted 'native' Burkholderia symbionts outcompete non-native bacteria in the gut of their bean bug host, even though they are able to establish in the absence of the 'native' symbiont. Finally, Ranger et al. [17] showed that ambrosia beetles selectively colonise physiologically stressed trees, which have a high ethanol titre due to anaerobic respiration. The vertically transmitted fungal symbionts of these beetles have evolved to detoxify the ethanol whereas competing weedy fungi remain inhibited.

Competition-based screening seems particularly apt for the establishment of protective microbiomes $[12,13]$ because although the production of bioactive compounds such as antibiotics is highly complex, leading to a wide diversity of chemical structures and resistance mechanisms, natural selection is expected to reinforce the correlation between the traits of antibiotic production and antibiotic resistance, since production without resistance by the same cell would be suicidal. Scheuring and $\mathrm{Yu}$ [12] thus proposed that if a host species provides copious food resources and if non-producer strains have the faster growth rate, the microbiome becomes 'bistable', meaning that two equilibrium outcomes are possible. If the non-producers start with a higher initial abundance, their faster growth rate allows them to take over the host space and exclude the antibiotic-producers before the latter can produce high concentrations of antibiotic, whereas if the slower-growing antibiotic producers start with a higher initial abundance, they have a large enough population to produce enough antibiotic to kill off non-producers and grow to take over the host space. In this light, vertical transmission of an antibiotic producer strain by the host can ensure that the microbiome always starts with a higher abundance of antibiotic producers.

The conservative assumption in this argument is that the non-producers are given the faster growth rate, which is likely, since they do not pay the cost of antibiotic production and since non-producers are more common than producers in the environment, which implies that in any random sample of microbial colonisers from the environment, at least some of the nonproducers are likely to have faster growth rates than producers. Under such circumstances, vertical transmission of a primary antibiotic producer can result in the selective horizontal acquisition (recruitment) of additional, antibiotic-producing bacteria from the environment, because antibiotic-producers should be superior competitors in food- and antibiotic-filled environments. The resulting, more diverse, microbiomes are then largely purged of free-riding non-beneficial strains $[8,11,12]$. Previous research has shown that the protective, cuticular microbiome of Acromyrmex echinatior leaf-cutting ants (Formicidae, Attini) is an ideal model system to test 
whether screening can act as a leash in the ecosystemon-a-leash perspective $[8,18]$.

Acromyrmex worker ants forage for fresh leaf fragments to provision their co-evolved fungus garden mutualist Leucoagaricus gongylophorus [19, 20]. The fungal cultivar produces gongylidia, nutrient-rich swellings that are the sole food source for the queen and larvae [21, 22] and the predominant food source for the workers who also ingest plant sap and fruit juice in addition to fungal food [23]. However, Leucoagaricus is at risk of being parasitised by the specialised, coevolved mould Escovopsis weberi, which can degrade the fungal cultivar and also cause severe ant paralysis and mortality [2427]. To prevent infections, leaf-cutting ants have evolved a range of weeding and grooming behaviours [28-30], and A. echinatior and other Acromyrmex species also maintain filamentous actinomycete bacteria that grow as a white bloom on the cuticles of large workers. These bacteria produce antimicrobials that inhibit the growth of $E$. weberi [24, 26, 31]. In Panama, where almost all fieldwork on this multipartite symbiosis has been carried out, the cuticle of Acromyrmex workers is dominated by one of two vertically transmitted strains of Pseudonocardia, named P. octospinosus (Ps1) and P. echinatior (Ps2) $[18,32,33]$.

Newly eclosed large workers are inoculated with the vertically transmitted Pseudonocardia strain by their nestmates. This blooms over the cuticle, reaching maximum coverage after ca. 6 weeks, before shrinking back to the propleural plates as the ants mature to assume foraging tasks [34, 35]. However, several studies have also identified other actinomycete strains on the propleural plates of $A$. echinatior, which are presumed to be acquired from the environment $[18,36-40]$. This includes species of the bacterial genus Streptomyces, which have been identified on ants maintained in laboratorybased colonies [36-38], as well as in a 16S rRNA gene amplicon sequencing study of ants sampled from their native environment, although many of these could also have been close relatives of Streptomyces [18]. Species of this actinomycete genus produce a variety of antimicrobials so their additional presence may suggest a form of multi-drug therapy against Escovopsis [37-39]. However, these putative functions remain enigmatic because Streptomyces symbionts were never found on the callow workers [18] that execute hygienic and defensive fungus garden tasks [35]. In terms of resources, the propleural plates have a high concentration of tiny subcuticular glands, which are presumed to supply the cuticular microbiome with resources [41]. These plates can thus be conjectured to create the food-rich but antibioticladen demanding environment that competition-based screening assumes, because the vertically transmitted native Pseudonocardia symbiont always colonises the propleural plates first [12, 35]. We have previously shown that both $P$. octospinosus and $P$. echinatior encode and make antibacterial compounds that inhibit multiple unicellular bacteria but do not inhibit Streptomyces species [32]. However, the other key elements of the screening hypothesis have remained untested.

The present study carries out a series of tests of competition-based screening, using the cuticular microbiome of $A$. echinatior as an open symbiotic ecosystem where the host nonetheless holds the leash, by controlling resource provisioning rates and by having first inoculated workers with Pseudonocardia. The co-adapted defensive Pseudonocardia symbiont, which is advantaged due to the priority effects associated with vertical transmission, is then expected to skew subsequent competition amongst an unspecified number of symbionts randomly colonising from the environment. We used RNA-SIP (stable isotope probing) to show that the ants provide a food resource on their cuticles that is consumed by multiple bacterial species, thus showing both that the resource is public and that multiple bacterial species can become established in the cuticular microbiome. We then use RNA sequencing to show, in vivo, that mutualistic $P$. octospinosus and $P$. echinatior strains express antibacterial biosynthetic gene clusters (BGCs) on the ant cuticle. Next, we show that diffusible metabolites of these Pseudonocardia species exhibit broadspectrum antibacterial activity in vitro, but only weakly inhibit Streptomyces species isolated from the cuticular microbiome, which we separately and directly show are resistant to a range of antibiotics. Finally, we demonstrate that these elements result in biassed competition, by using in vitro competition experiments to show that slower-growing Streptomyces species can competitively exclude faster-growing non-antibacterial-producing species, but only when grown on media infused with Pseudonocardia metabolites.

\section{Results}

\section{The host provides public resources to its cuticular} microbiome

RNA-SIP tracks the flow of heavy isotopes from the host to the RNA of microbial partners that metabolise hostderived resources [42-44]. Labelled and unlabelled RNA within a sample can be separated via ultracentrifugation and fractionation; these fractions can be used as templates for $16 \mathrm{~S}$ rRNA gene amplicon sequencing so that the bacterial taxa that do (and do not) use host-supplied resources can be identified [44]. RNA was chosen over DNA in this experiment to increase the chances of labelling over a short time frame; RNA labelling requires active transcription, whereas DNA labelling requires DNA replication. Actinomycetes, in particular, only massively upregulate DNA replication when they sporulate. A 
shorter period was also desirable as it reduces any crossfeeding between bacterial species, although we note that any resources acquired by cross-feeding count as public in the screening model because they also, eventually, contribute to bacterial growth and metabolism. Three replicate groups of 22 mature worker ants were fed a $20 \%(\mathrm{w} / \mathrm{v})$ solution of either ${ }^{12} \mathrm{C}$ or ${ }^{13} \mathrm{C}$ glucose for 10 days, and then propleural plates were dissected out for total RNA extraction (Additional file 1: Fig. S1). Control feeding experiments demonstrated that a fluorescently labelled glucose-water diet was not transferred to the surface of the propleural plate region of the ants during feeding, and the ants were only ever observed to feed using their mandibles, such that their propleural plates never came into direct contact with the liquid diet (Additional file 1: Fig. S2).
Following cDNA synthesis, 16S rRNA gene amplicon sequencing showed that filamentous actinomycetes dominate the propleural plate samples, making up 76.6\% and $78.0 \%$ of the total, unfractionated, cDNA samples from ${ }^{12} \mathrm{C}$ and ${ }^{13} \mathrm{C}$ fed ants, respectively (Fig. 1). The most abundant bacterial genera were Pseudonocardia, $35.8 \%$ and $38.1 \%$ in ${ }^{12} \mathrm{C}$ and ${ }^{13} \mathrm{C}$ samples, respectively, and Streptomyces, $19.7 \%$ and $20.5 \%$, respectively. Wolbachia made up $22.8 \%$ and $19.6 \%$, respectively. Wolbachia are known to be associated with the thoracic muscles of A. echinatior worker ants where they may have an unspecified mutualistic function $[45,46]$. We conclude that these reads came from the trace amount of residual ant tissue on the dissected propleural plates and do not consider them further. More than $95 \%$ of the Pseudonocardia 16S rRNA gene reads in unfractionated RNA
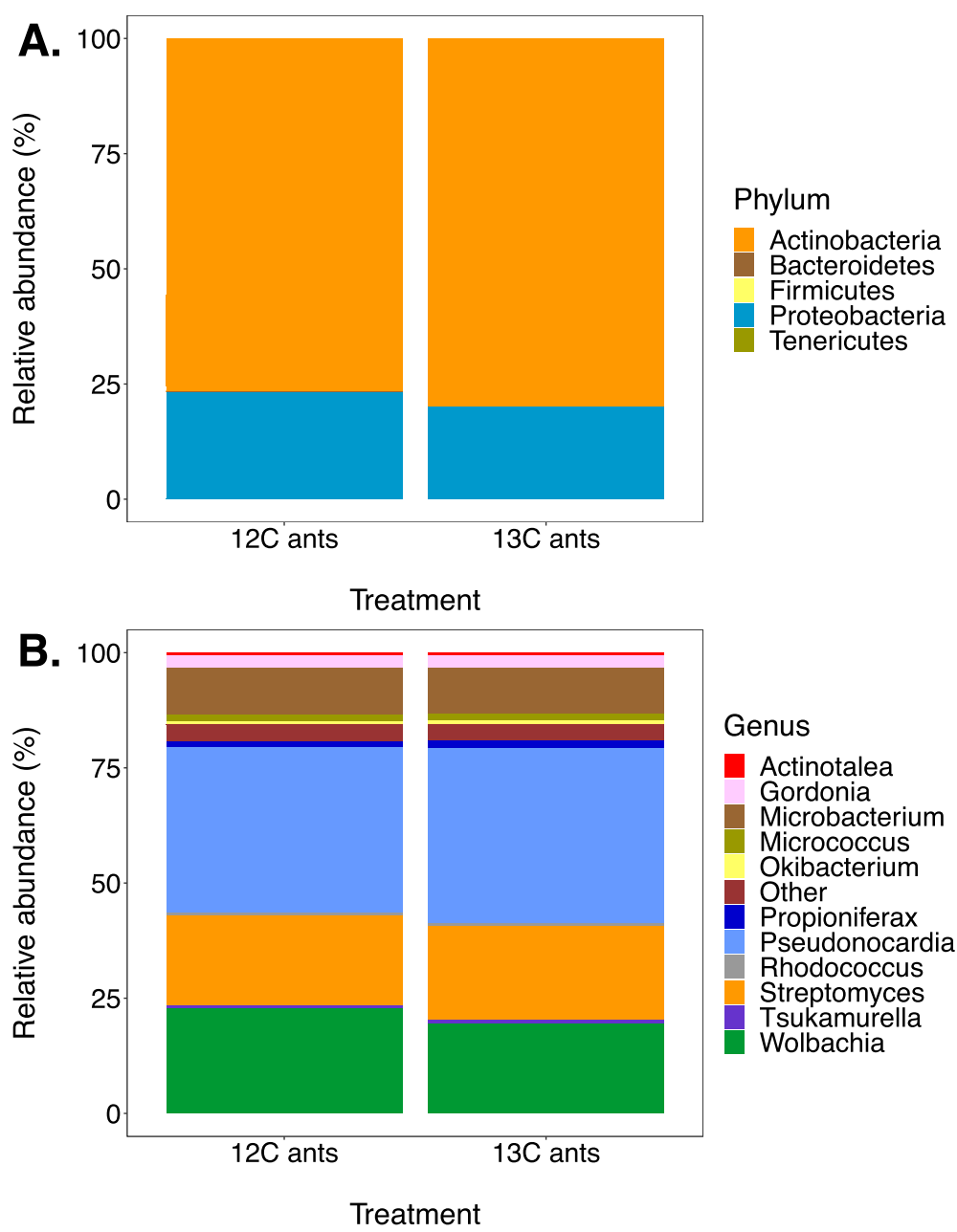

Fig. 1 Frequencies of bacteria at different taxonomic levels in unfractionated RNA samples from the propleural plates of ants provided with a 20\% (w/V) solution of either ${ }^{12} \mathrm{C}$ - or ${ }^{13} \mathrm{C}$-labelled glucose. A Phylum resolution, showing that $>75 \%$ were Actinobacteria. The remaining reads almost all corresponded to Wolbachia (Proteobacteria) so the three other phyla do not appear in the bars (total relative abundance of $0.6 \%$ and $0.4 \%$ in ${ }^{12} \mathrm{C}$ and ${ }^{13} \mathrm{C}$ fractions, respectively). As Wolbachia is not part of the cuticular microbiome (see text), these results show that the cuticular microbiome is completely dominated by Actinobacteria. B Genus-level resolution showing that the cuticular microbiomes are dominated by the native Pseudonocardia symbiont followed by appreciable fractions of horizontally acquired Streptomyces species and a series of other Actinobacteria at low prevalence 
samples were identical in sequence to a single $P$. octospinosus mutualist strain $[18,32]$. The presence of Streptomyces and other actinomycete bacteria is consistent with the interpretation of previous studies that environmentally acquired, antibiotic-producing actinomycetes can establish in the cuticular microbiome [36-40, 47], despite these large workers having first been inoculated with the vertically transmitted symbiont Pseudonocardia [18].

Caesium trifluoroacetate density gradient ultracentrifugation was used to separate the ${ }^{13} \mathrm{C}$-labelled 'heavier' RNA from the un-labelled ${ }^{12} \mathrm{C}$ 'lighter' RNA within the ${ }^{13} \mathrm{C}$-fed samples (Additional file 1: Fig. S1). RNA samples from the control ${ }^{12} \mathrm{C}$ dietary treatment also underwent density gradient ultracentrifugation. The resulting gradients were fractionated by buoyant density ultracentrifugation, and cDNA from each fraction was used in quantitative RT-PCR reactions (Additional file 1: Figs. S3 \& S4). This demonstrated that 16S rRNA gene transcripts had shifted to higher buoyant densities under the ${ }^{13} \mathrm{C}$ dietary treatment (Additional file 1: Fig. S3). A peak in transcripts was detected at an average buoyant density of $1.789 \mathrm{~g} \mathrm{ml}^{-1}$ ( $\pm 0.003 \mathrm{SD}$ ) under the ${ }^{12} \mathrm{C}$ treatment, but this had shifted to a significantly higher buoyant density $\left(1.797 \mathrm{~g} \mathrm{ml}^{-1} \pm 0.001, P=0.016\right.$ in a two-sample $t$-test) under the ${ }^{13} \mathrm{C}$ dietary treatment (Additional file 1 :
Fig. S4). This is consistent with the heavier ${ }^{13} \mathrm{C}$ isotope being incorporated into the RNA of cuticular bacteria, due to the metabolism of labelled host resources (Additional file 1: Fig. S4).

Fractions spanning the peaks in transcript number were selected for $16 \mathrm{~S}$ rRNA gene amplicon sequencing (Additional file 1: Fig. S4). The relative abundances of taxa identified by sequencing were further normalised using the percentage of $16 \mathrm{~S}$ rRNA gene transcripts detected in each fraction in the GPCR experiments; this was to account for the differences in the absolute abundance of $16 \mathrm{~S}$ rRNA gene transcripts detected in each fraction and also to facilitate the comparison of replicates within and across treatments, which differed in the total amount of RNA extracted. Sequencing confirmed that transcripts from actinobacterial genera had shifted to higher buoyant densities under the ${ }^{13} \mathrm{C}$ treatment (Fig. 2A-C). For example, the abundance of the vertically transmitted Pseudonocardia symbiont tracked changes in the total number of 16S rRNA gene transcripts that had been identified using qPCR (Fig. 2A, Additional file 1: Fig. S4). Specifically, Pseudonocardia sequences were detected at an average relative abundance of $36.30 \%( \pm 7.22)$ in the peak fractions of the ${ }^{13} \mathrm{C}$ treatment (average buoyant density of $1.797 \mathrm{~g} \mathrm{ml}^{-1} \pm$ 0.001, Fig. 2A) - these fractions contained an average of

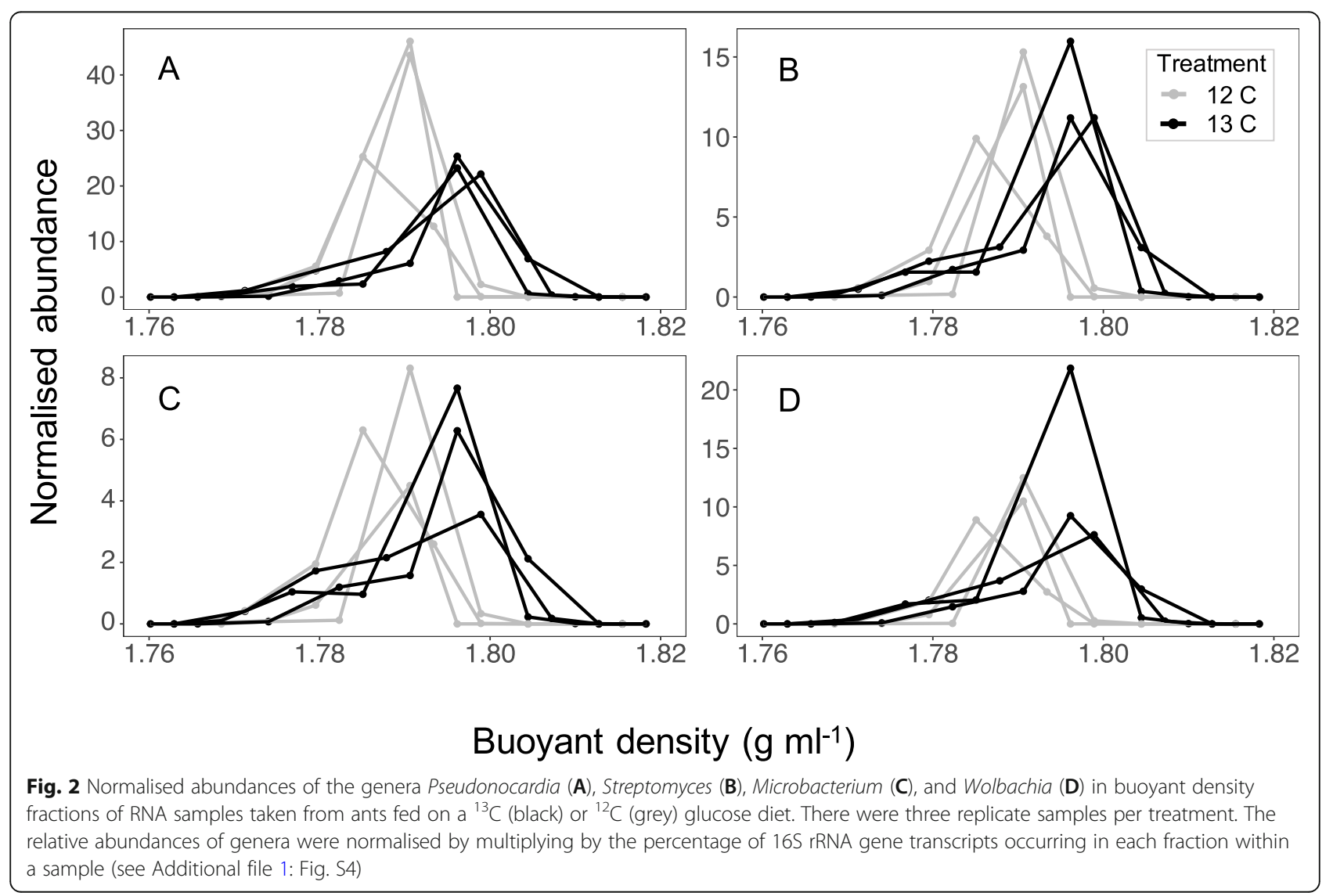


$66.45 \%$ ( \pm 12.34$)$ of the total number of $16 \mathrm{~S}$ rRNA gene transcripts identified within a sample (Additional file 1: Fig. S4), giving a mean normalised abundance of $23.57 \pm$ 1.67 (Fig. 2A). Although Pseudonocardia sequences were also detected in fractions of equivalent buoyant density under the ${ }^{12} \mathrm{C}$ treatment (Fig. 2A), these fractions contained less than $2 \%$ of the total number of $16 \mathrm{~S}$ rRNA gene transcripts within these samples (Additional file 1: Fig. S4); hence, a mean normalised abundance of $0.78 \pm$ 1.29 was recorded (Fig. 2A). The abundance of Pseudonocardia transcripts instead peaked at a significantly lower buoyant density $\left(1.789 \mathrm{~g} \mathrm{ml}^{-1} \pm 0.003, P=0.016\right)$ under the ${ }^{12} \mathrm{C}$ treatment.

In addition to Pseudonocardia, horizontally acquired taxa, including Streptomyces and Microbacterium, also showed similar shifts to higher buoyant densities under the ${ }^{13} \mathrm{C}$ treatment and were abundant in peak fractions of ${ }^{13} \mathrm{C}$ samples (Fig. 2B, C). For example, Streptomyces had an average normalised abundance of $12.790 \pm 2.758$ in peak fractions of the ${ }^{13} \mathrm{C}$ samples. This indicates that ant-derived resources were not solely available to the Pseudonocardia, which would otherwise have dominated the ${ }^{13} \mathrm{C}$ heavy fractions, but are available to, and taken up by, all bacteria on the cuticle.

The frequency of Wolbachia also shifted to heavier fractions under the ${ }^{13} \mathrm{C}$ heavy treatment (Fig. 2D). Since Wolbachia are extracellular muscular tissue symbionts in this particular symbiosis [45], this finding supports the interpretation that resources were supplied to $\mathrm{cu}$ ticular bacteria by the ant hosts and not taken directly from the glucose water. This interpretation is also backed by isotope ratio mass spectrometry (IRMS), which showed that surface-washed ants incorporate a significant amount of the ${ }^{13} \mathrm{C}$ from their glucose diet into their bodies (Additional file 1: Fig. S5), and by direct fluorescent microscopy demonstrating that the glucose water was not transferred to the propleural plate (Additional file 1: Fig. S2). Note that abundances of all other taxa become ca. 20\% and ca. 50\% higher after excluding Wolbachia in the ${ }^{12} \mathrm{C}$ and ${ }^{13} \mathrm{C}$ treatment, respectively (Fig. 2), i.e. when considering only the cuticular microbiome.

\section{Antibacterial BGCs are expressed by Pseudonocardia on the ant cuticle}

We previously generated high-quality genome sequences for five Pseudonocardia octospinosus and five P. echinatior strains isolated from Acromyrmex echinatior ant colonies and identified several BGCs (biosynthetic gene clusters) in each of their genomes that are associated with antimicrobial activity [32]. To establish if these BGCs are expressed in vivo on the ant cuticle, total RNA was extracted and sequenced from the propleural plates of ants in the captive colonies Ae088 (which hosts a vertically transmitted $P$. echinatior strain) and Ae1083 (which hosts a $P$. octospinosus strain) (Additional file 1: Table S1 [32, 37, 47-56]). A single RNA extraction was carried out for each colony, with each sample consisting of the pooled propleural plates of 80 individual ants. RNA samples were sequenced, and the resulting reads were quality filtered and mapped to their corresponding Pseudonocardia reference genomes [32] (Additional file 1: Table S2). Both Pseudonocardia species showed very similar patterns of gene expression in vivo, with genes involved in the production of secondary metabolites, including antibiotics (as classified by KEGG) being expressed at similar levels by both Pseudonocardia strains on the cuticle of $A$. echinatior ants (Additional file 1: Fig. S6).

BGCs that are shared by the $P$. octospinosus and $P$. echinatior strains (Additional file 1: Table S3 [32]) displayed remarkably similar patterns of in situ expression on the propleural plates (Fig. 3A). For both Pseudonocardia species, the most highly expressed BGCs encoded proteins responsible for the synthesis of the compound ectoine and a putative carotenoid terpene pigment (cluster D and F, Fig. 3A). Such compounds are known to provide protection against abiotic stressors such as desiccation and high concentrations of free radicals which are often associated with biofilms [57-59]. Also expressed on the propleural plates is a shared BGC encoding a putative bacteriocin (cluster E, Fig. 3A), which belongs to a family of ribosomally synthesised posttranslationally modified peptide (RiPP) antibiotics produced by many species of bacteria [60-62]; these are known to prevent the formation of biofilms by other microbial species $[60,63]$. In contrast, a shared type 1 PKS gene cluster, encoding nystatin-like antifungal compounds [32, 37], had very low expression in the P. echinatior strain and was not expressed at all in the $P$. octospinosus strain (cluster C, Fig. 3A). This suggests that additional cues, such as direct exposure to $E$. weberi may be required to activate this BGC, since both Pseudonocardia strains produce inhibitory antifungals when confronted with E. weberi in vitro (Additional file 1: Fig. S7). A Pseudonocardia strain isolated from Acromyrmex ants has also previously been shown to produce nystatin-like compounds in vitro [37]. The most highly expressed BGCs unique to $P$. echinatior (cluster P, Fig. 3C) or P. octospinosus (cluster J, Fig. 3B) are both predicted to encode bacteriocins.

Taken together, the results of the RNA-SIP and RNA sequencing experiments are consistent with both previous empirical research $[18,33]$ and the screening hypothesis $[12,13]$ : the ant host provides public resources to its cuticular microbiome via glandular secretions [41] for which colonising ectosymbionts may compete. This is always after the native Pseudonocardia has established 


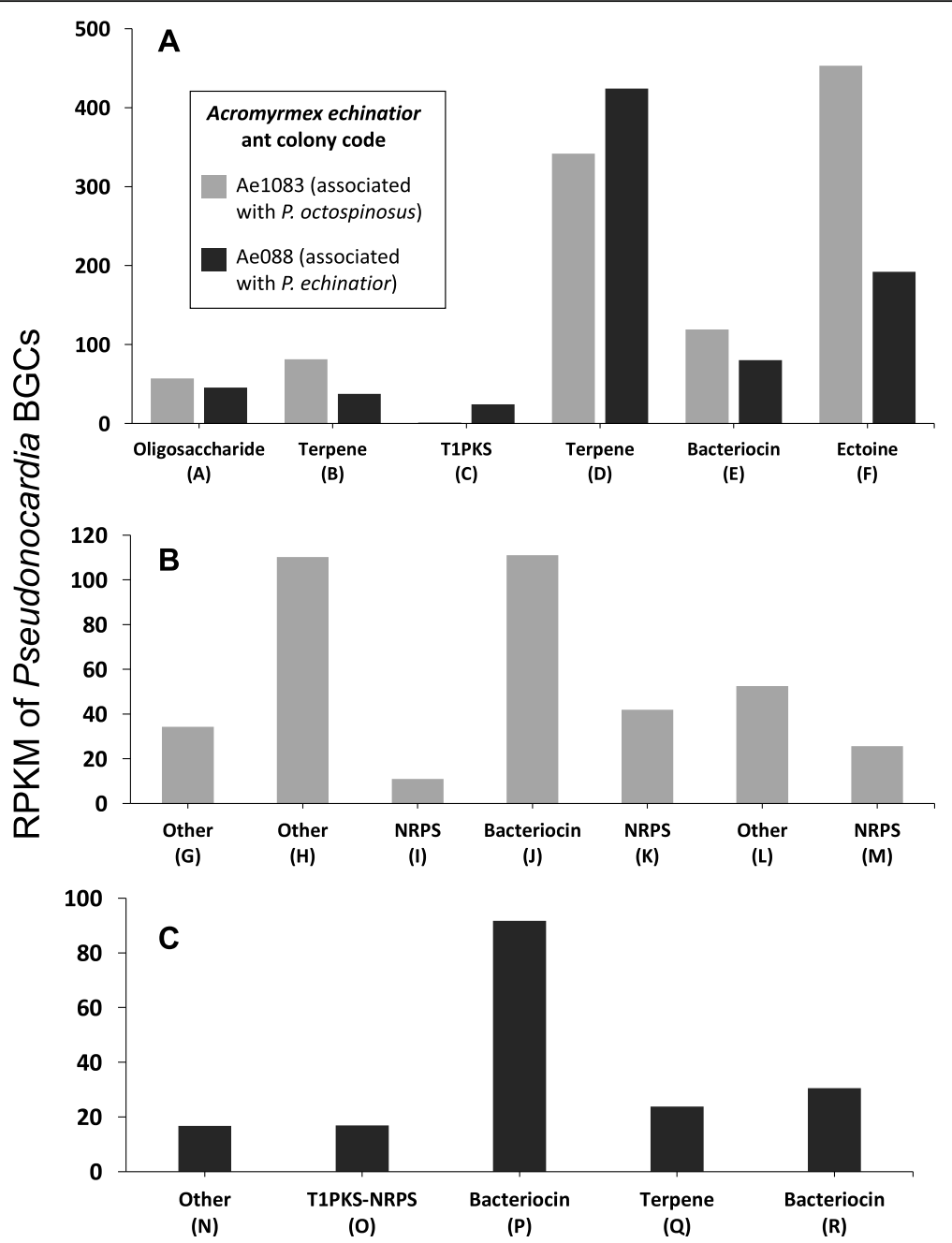

Fig. 3 Expression (in reads per kilobase of transcript per million mapped reads (RPKM)) of $\mathbf{A}$ biosynthetic gene clusters that are shared between the two Pseudonocardia species, B biosynthetic gene clusters that are unique to P. octospinosus (colony Ae1083), and $\mathbf{C}$ biosynthetic gene clusters that are unique to P. echinatior (colony Ae088). Biosynthetic gene cluster codes relate to Additional File 1: Table S3. The results from each colony were derived from a pool of 80 ants

and gained dominance, which creates a demanding cuticular environment for any additional strain to invade.

\section{Pseudonocardia antibacterials create a demanding environment for non-antibiotic-producing bacteria} Next, we compared the growth rates of antibioticproducing Streptomyces strains and non-antibioticproducing bacteria on antibiotic-infused and control media. All strains were isolated from soil or fungusgrowing ant nests (Additional file 1: Table S1). The antibiotic-infused media were created by growing lawns of 17 Pseudonocardia isolates (Additional file 1: Table S1) on SFM agar, while control media were inoculated with $20 \%$ glycerol. After a 6 -week incubation period, the agar medium was flipped to reveal a surface for colonisation. The non-producer strains grew more quickly on the non-demanding control media while the antibiotic- producers grew more quickly on the demanding Pseudonocardia-infused media, producing a highly significant statistical interaction effect $\left(n=975, \chi^{2}=45.86, \mathrm{df}=2\right.$, $P<0.0001$; Fig. 4). There was also a significant main effect of Pseudonocardia genotype, with both nonproducers and producers exhibiting a lower growth rate on $P$. echinatior (Ps2)-infused media than on P. octospinosus (Ps1)-infused media (linear mixed-effects model, $n$ $=915, X^{2}=24.55, \mathrm{df}=1, P<0.0001$, control-media data omitted for this analysis). This outcome is consistent with the observation by Andersen et al. [18] that Acromyrmex colonies hosting Ps2-dominated cuticular microbiomes were less prone to secondary invasion by other bacteria.

To test the hypothesis that producer strains are generally resistant to antibiotics, which would confer competitive superiority in an antibiotic-infused host environment [12], we 


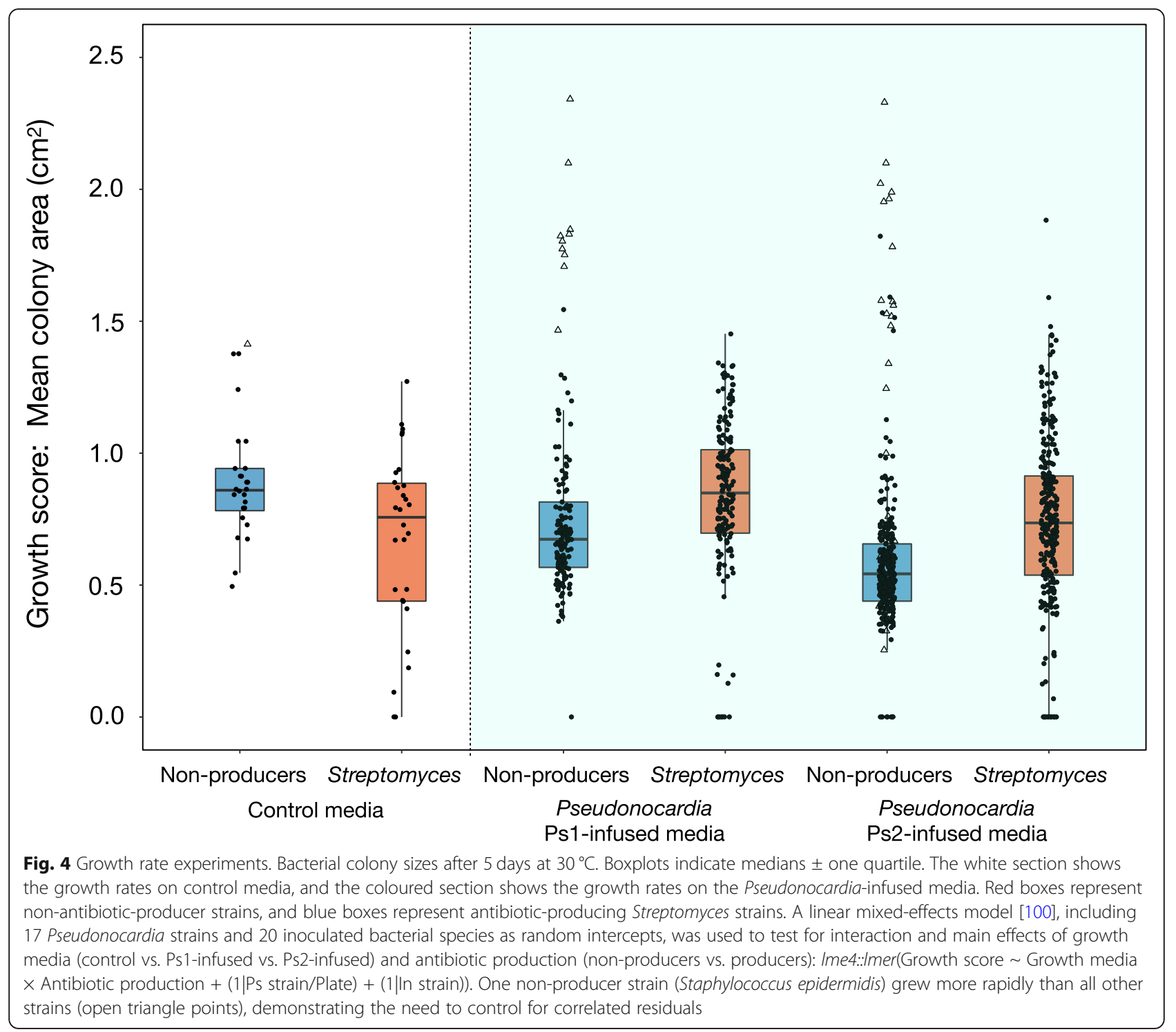

grew ten producer strains (all Streptomyces spp.) and ten non-producer strains (Additional file 1: Table S1) in the presence of eight different antibiotics (Additional file 1: Table S4), representing a range of chemical classes and modes of action. After 7 days, the lowest effective concentration (LEC, lowest concentration with inhibitory effect) and minimum inhibitory concentration (MIC, lowest concentration with no growth) scores were assigned on a Likert scale of 1-6, where a score of 1 was no resistance and a score of 6 was resistance above the concentrations tested [64]. Antibiotic-producer strains exhibited greater levels of resistance, measured by both LEC (Wilcoxon two-sided test, $W=94.5, P=0.0017)$ and MIC scores $(W=80, P=$ 0.0253); $P$-values were corrected for two tests (Fig. 5).

We also performed growth rate experiments and measured antibiotic resistance profiles with resident nonantibiotic-producing strains that had been directly isolated from cuticular microbiomes. These strains had significantly slower growth rates overall, even on control media without antibiotics, suggesting that these strains are just transient environmental contaminants (Additional file 1: Fig. S8). These resident non-producer strains also demonstrated high levels of resistance as expected (Additional file 1: Fig. S9), given that they had been isolated from ant cuticles.

\section{Pseudonocardia antibacterials allow Streptomyces to} competitively exclude non-antibiotic-producing bacteria

Finally, to test whether producer strains have a competitive advantage in the demanding environment created by Pseudonocardia, we pairwise-competed two of the Streptomyces producer strains, named S2 and S8 (Additional file 1: Table S1), against each of 10 environmental non-producer strains on normal and on antibiotic-infused media. In the latter 


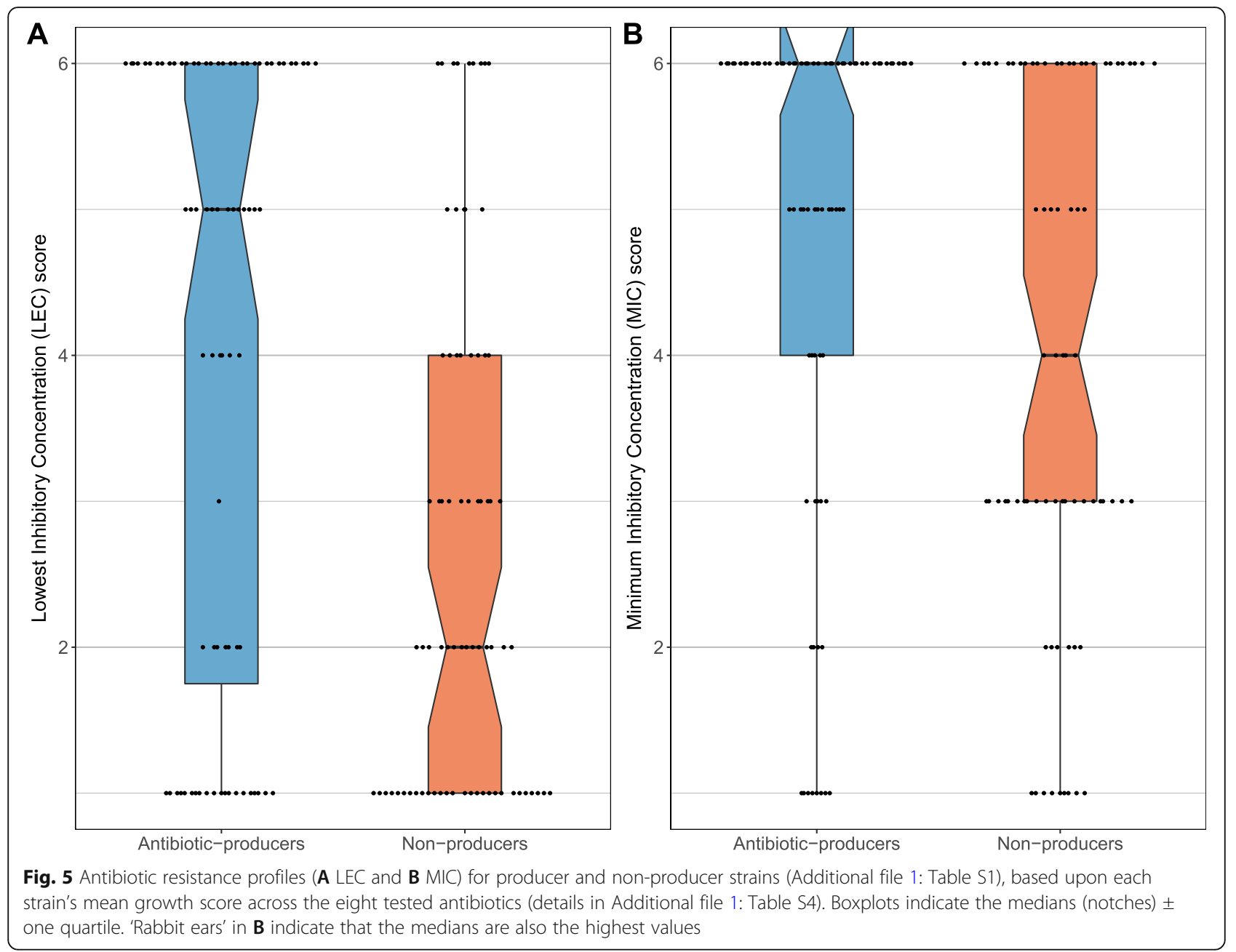

case, Pseudonocardia was again grown on agar plates before turning the agar over and coinoculating producer and nonproducer test strains. On normal growth media, Streptomyces were more likely to lose to non-producers, but on Pseudonocardia-infused media, Streptomyces were more likely to win (general linear mixed-effects model; S8 on Ps1infused media: $n=129, \chi^{2}=103.6, \mathrm{df}=1, P<0.0001$; S2 on Ps2-infused media: general linear mixed-effects model, $n=94, \chi^{2}=87.9, \mathrm{df}=1, P<0.0001$; Fig. 6).

\section{Discussion}

We tested screening theory using the external (cuticular) microbiome of the leaf-cutting ant Acromyrmex echinatior as an experimental model. We used RNA-SIP to show that an animal host is directly feeding its microbiome (Fig. 2). We further show that the resource is public, meaning that the resource is used for growth not only by vertically transmitted Pseudonocardia but also by multiple species of environmentally acquired bacteria on the ant cuticle (Fig. 2). We then demonstrated, in two separate ant colonies, that both $P$. octospinosus and $P$. echinatior strains express antibacterial biosynthetic gene clusters (BGCs) on the ant cuticle (Fig. 3). We next showed that the two species of actinobacteria have broad-spectrum antibacterial activity against environmental isolates in vitro and, importantly, have a weaker effect on Streptomyces than on non-producers (Fig. 4), consistent with these Streptomyces species being resistant to a range of antibiotics (Fig. 5), which is typical for this genus. Finally, we used in vitro competition experiments to demonstrate that Streptomyces species can competitively exclude faster-growing bacteria that do not make antibiotics, but only when the competing species are grown on media infused with Pseudonocardia metabolites (Fig. 6).

Although feeding treatments for the RNA-SIP experiment were conducted over a short time-frame (10 days), it is possible that some of the bacterial symbionts acquired resources indirectly, by using labelled metabolites produced by other microbes that were feeding directly on the ant-derived resources. However, cross-feeding is 


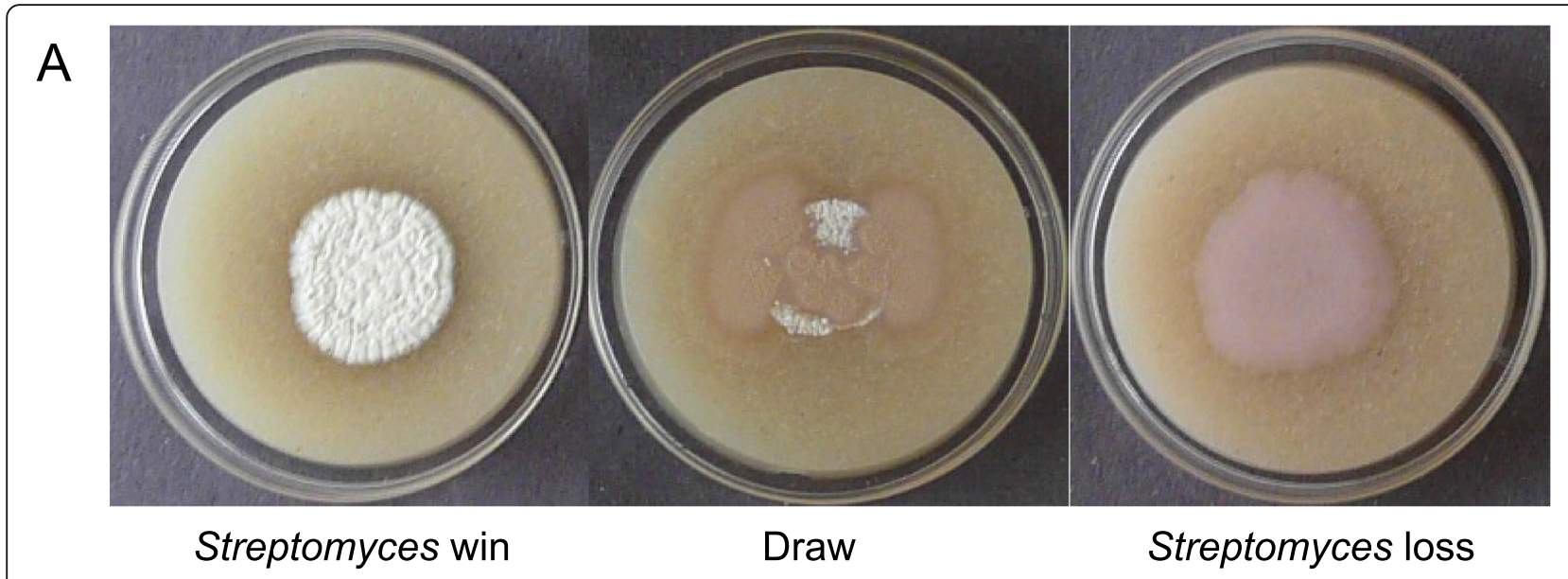

B Competitive outcome for Streptomyces strain $\mathrm{S8}$

Competitive outcome for Streptomyces strain S2
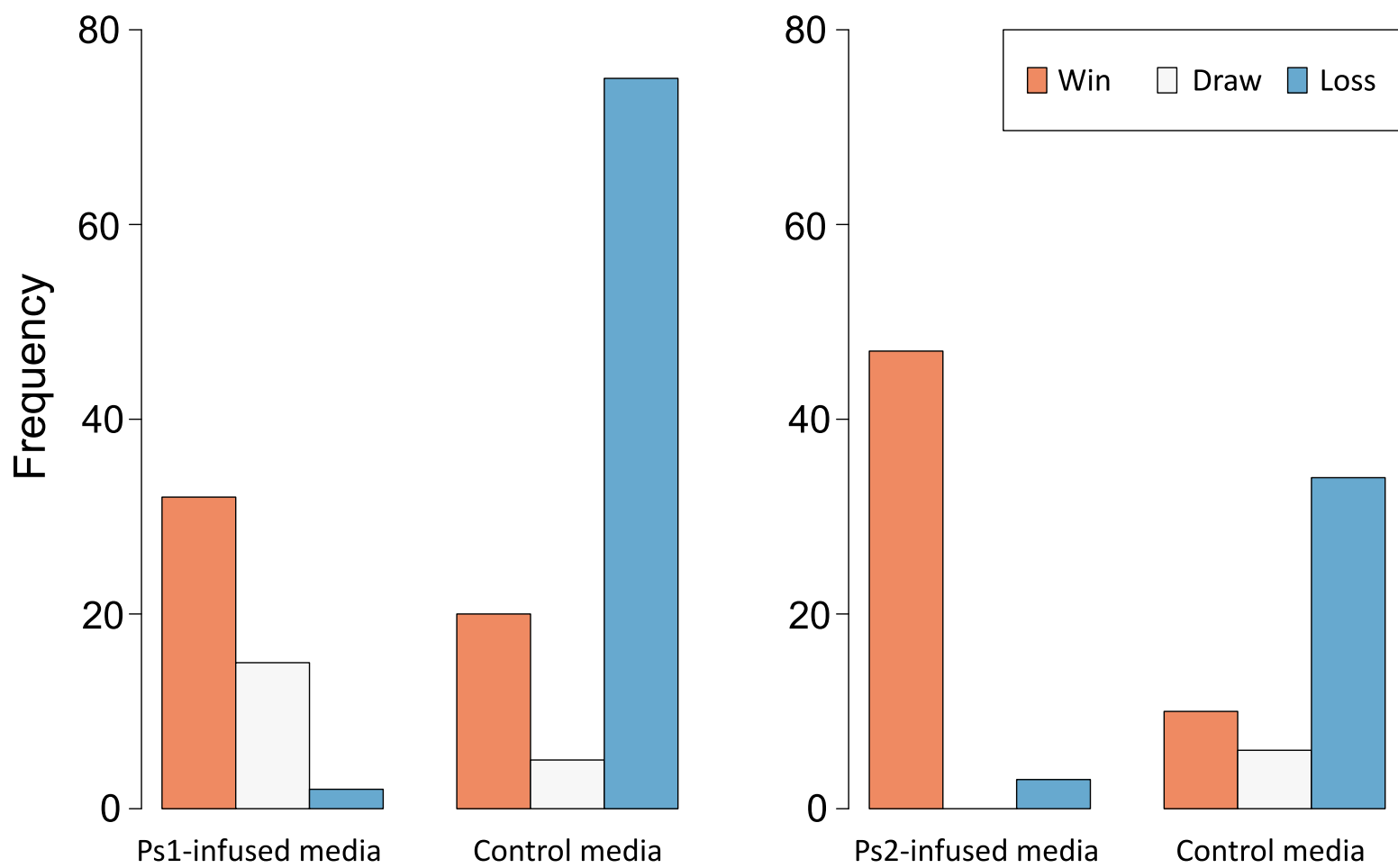

Fig. 6 Pairwise competition experiment, scoring the frequency of producer wins. A Representative images of agar plates at 5 days postinoculation showing examples of the three competitive outcomes: win (producer S2 vs. non-producer St3 on Ps2 media), loss (producer S8 vs. non-producer St3 on control media), and draw (producer S2 vs. non-producer St3 on control media) (strain details in Additional file 1: Table S1). B Bar charts of competitive outcomes for the two Streptomyces producer strains (S8 and S2; Additional file 1: Table S1). Each Streptomyces strain was individually competed against ten different non-antibiotic-producer strains. Streptomyces is more likely to win on Pseudonocardia-infused media. A general linear mixed-effects model, with ten non-antibiotic-producer strains as a random intercept, was used to test for the effect of medium (control vs. Ps-infused) on the competitive outcome (win vs. loss). For analysis, draws were omitted. S8 on Ps1-infused media: $n_{P_{5} 1 \text {-infused }}=34$, $n_{\text {Control }}=95, X^{2}=103.6, d f=1, P<0.0001 ;$ S2 on Ps2-infused media: general linear mixed-effects model, $n_{\text {Ps2-infused }}=50, n_{\text {Control }}=44, X^{2}=87.9$, $\mathrm{df}=1, P<0.0001$. Ime4:..g/mer(outcome $\sim$ medium $+(1 \mid$ non-producer strain), family = binomial)

still consistent with the food resource being public, and thus consistent with competition-based screening, since multiple bacterial species, including horizontally acquired actinobacteria, are still taking up host-supplied resources for growth, albeit indirectly, thus fuelling competition amongst species for host space. 
Taken together, these results are consistent with the hypothesis that competition-based screening is a plausible mechanism for maintaining the integrity of the coadapted mutualism between the leaf-cutting ant farming symbiosis and its defensive microbiome, predicted to be conditional on the vertically transmitted Pseudonocardia symbiont always being the first to establish and create a demanding environment. This priority establishment is invariably the case because callow large workers are inoculated by their nestmates within $24 \mathrm{~h}$ of emerging from their pupae [34]. Pseudonocardia is also never competitively excluded from the microbiome, as predicted by Scheuring and $\mathrm{Yu}$ [12] and empirically shown by Andersen et al. [18]. Indeed, initial advantages of early colonisation and nutrients allow Pseudonocardia to form a dense growth before additional microorganisms can colonise the ant cuticle. The new results reported here illustrate the tractability of the cuticular leaf-cutting ant microbiome, which is accessible to experimentation and for which the adaptive benefit to the ant hosts is clearly defined and explicitly testable: defence against specialised Escovopsis pathogens and colony collapse [3, $25,37,65]$. Our present results are consistent with our previous hypothesis that the vertical transmission of Pseudonocardia results in Streptomyces strains being superior contenders for secondary acquisition [12].

An alternative hypothesis to screening is that the ants selectively acquire additional antibiotic-producing bacteria via a lock-and-key mechanism, in the same way that leguminous plants recognise Rhizobium symbionts via species-specific Nod-factor signalling molecules [66]. However, lock-and-key signalling requires tight coevolution between all candidate symbiont and host lineages (see [67] for one model), which could be true for the Acromyrmex- associated Pseudonocardia species but is highly unlikely for the other genera across the phylum Actinobacteria that can become established on the ant cuticle (Fig. 1). In contrast, legumes associate with only one genus of root-nodule symbionts, Rhizobium.

The petri dish competition experiments have the important advantage of allowing unambiguous scoring of wins, losses, and draws on media with and without Pseudonocardia. However, future work should focus on adding realism, since on the cuticle, competition is taking place amongst multiple species, with variation in colonisation order, the cuticular microenvironment, and resource provisioning rates [13]. However, although it is possible to prevent the establishment of Pseudonocardia on newly eclosed workers [34], the technical challenge will be to score relative species abundances (i.e. winners and losers) from sequencing datasets, in the face of cryptic species biases (see [68] for a discussion of this problem and [69] for a potential solution). A complementary approach would be to compare competition in vitro and in vivo with wild-type and knock-out strains of Pseudonocardia that are unable to produce the antimicrobial compounds observed in RNA-seq experiments. However, such an experiment would require extensive genetic modification, which has so far proven very challenging in Pseudonocardia.

Although competition has not been demonstrated via addition or removal experiments, we have shown clear resource-use overlap via the RNA-SIP experiment (Fig. $1)$ and the capacity for competitive exclusion via the petri dish experiment (Fig. 6). Combined with the capacities for exponential growth and for antibiotic production in the Streptomyces strains, we have a strong expectation of both scramble and interference competition in the attine cuticular microbiome.

The nature and origin of the host-derived resources remain elusive. Previous studies have observed that Pseudonocardia grows in or above specialised cavities on the ant cuticle, called foveae, that are underlain by structures that appear to be exocrine glands [41]. However, it has not been experimentally confirmed that these glands are the source of resources supplied to the cuticular microbiome. Another study has shown that metapleural gland secretions (the only other exocrine secretion that could reasonably spread over the entire cuticle) have no influence on the early exponential growth phase of Pseudonocardia in callow ants [70]. Closure of these glands was shown to influence the growth of Pseudonocardia in older ants, but it was unclear if artificial manipulations had compromised other aspects of ant health in this instance [70].

There are several emerging techniques that might be used to locate and identify host-derived substrates in future experiments. For example, high-resolution secondary ion mass spectrometry imaging (NanoSIMS), combined with fluorescent in situ hybridisation (FISH) can be used to directly visualise the assimilation of stable isotopes by different bacterial taxa [71]. This technique has been used to visually track the bacterial metabolism of labelled compounds secreted by the mouse intestinal mucosa [72]. Similarly, Raman microspectroscopy creates a chemical fingerprint of a molecule or system and can identify compounds that have incorporated heavy isotopes via the spectral shifts that take place [73]. Techniques such as matrix-assisted laser desorption/ionisation time-of-flight (MALDI-TOF) imaging mass spectrometry could also be applied in a similar way and, although extremely challenging to carry out, has been used to image the distribution of an antifungal compound over the surface of $A$. echinatior ants [39].

Our results show that competition-based screening is a plausible mechanism for the acquisition of a diverse, antibiotic-producing microbiome. The natural follow-on question is whether this mechanism represents an 
Acromyrmex adaptation that improves defense against pathogens. We do know that Streptomyces species isolated from Acromyrmex ants can produce antifungals that inhibit the growth of Escovopsis in vitro [37-39, 47], but a direct test would require experimental removal and addition of Streptomyces (and/or antibiotic gene knock-outs), which so far have posed significant technical challenges. However, as noted above, Streptomyces symbionts have rarely been found on the callow workers [18] that tend the fungus garden [35]. Thus, the screening effect shown in our experiments might be an epiphenomenon of the mutualism between Pseudonocardia and Acromyrmex. In this case, the leafcutter ant system can be thought of as a tractable model for a screening phenomenon that may have adaptive significance elsewhere. Alternatively, the adaptive benefit of the extra actinobacterial species could be that they improve the protection of foraging workers from bacterial and fungal infections acquired outside the colony, thereby also indirectly protecting workers that interact more extensively with the fungus garden. Given that bacterial competition is known to stimulate antimicrobial export in vitro [74, 75], having multiple strains on individual ants may then be beneficial by stimulating the production of multiple different antimicrobial compounds. Indeed, Schoenian et al. [39] have directly visualised the production of the antimicrobial valinomycin by a Streptomyces strain on the cuticles of mature Acromyrmex workers. We also hypothesise that continuous competition against antibiotic-producing competitors may select against Pseudonocardia losing costly antimicrobial production genes as a side effect of its domestication by attine ants.

Our results are of broad significance because competition-based screening provides a mechanistic explanation for microbiomes to be evolutionary stable ecosystems-on-a-leash [8]; here, the host leash works by fomenting and biassing competition, via the combination of public resources and a vertically transmitted antibiotic-producing symbiont, to favour the establishment of antibiotic-producing bacteria [12]. This perspective is consistent with the idea that host-associated microbiomes can have both core members that co-adapt with host environments and non-adapted but still mutualistic members. Studies in other symbioses appear to support this dual evolutionary and ecological view [14, $16,17]$, both for an array of mutualistic symbioses with multicellular partners and for microbiomes more specifically. For instance, the actinomycete Bifidobacterium longum subsp. infantis dominates the guts of human neonates [11, 76]. In this case, the Bifidobacterium is an early coloniser because it is transmitted vertically from mother to child, and Bifidobacterium consumes a range of oligosaccharides provided in human breast milk to build up a large enough population that it can competitively exclude pathogen colonisers. We hypothesise that Bifidobacterium could act like Pseudonocardia and selectively favour the establishment of other Bifidobacterium species in the gut, at least until weaning. Similarities may also be seen in the ant species, Lasius fuliginosus, which stabilises its carton nest structures through the growth of a remarkably predictable community of fungi [77]. Experiments have shown that antimicrobial substances, originating from the ant body parts, are tolerated by these fungal associates and support their growth, enabling them to outcompete other species of doubtful loyalty to the symbiosis in the nest structure [77]. Similar processes may also play out during the establishment of plant root microbiomes [78-81] and could be open to manipulation in efforts to improve crop yields [82].

Future work on the Acromyrmex model system should include characterising the antibacterial molecules made by the symbiotic Pseudonocardia strains in vitro and in vivo and matching these compounds to the BGCs expressed on the ants. This will be challenging because ant-derived Pseudonocardia strains grow poorly on agar plates and rarely in liquid culture. Additionally, imaging mass spectrometry has, as yet, not been possible on the ants themselves.

\section{Methods}

\section{Ant colony collection and maintenance}

Colonies of A. echinatior (Hymenoptera, Formicidae, Attini) were collected from the Gamboa area of the Soberania National Park, Panama, between 2001 and 2014. Colonies Ae1083 and Ae088 (Additional file 1: Table S1) were maintained under controlled temperature conditions $\left(25^{\circ} \mathrm{C}\right)$ at UEA and fed a daily diet of bramble and laurel leaves. Additional colonies were maintained at the University of Copenhagen in rearing rooms at ca $25^{\circ} \mathrm{C}$ and $70 \%$ relative humidity, where they were fed with bramble leaves and occasional supplements of apple and dry rice.

\section{RNA-stable isotope probing RNA SIP ${ }^{13} \mathrm{C}$ feeding experiment}

Six replicate groups of 22 mature worker ants with visible bacterial growth on their propleural plates were selected from colony Ae1083 (Additional file 1: Table S1) and placed into $9-\mathrm{cm}$ petri dishes containing a $2 \times 2 \mathrm{~cm}$ square of cotton wool soaked in water. Following $24 \mathrm{~h}$ of starvation, three replicate groups of 22 ants were supplied with $300 \mu \mathrm{l}$ of a $20 \%{ }^{13} \mathrm{C}$ glucose solution (w/v, Sigma Aldrich), and the remaining three groups were supplied with $300 \mu \mathrm{l}$ of a $20 \%{ }^{12} \mathrm{C}$ glucose solution (w/v, Sigma Aldrich) for 10 days. Glucose solutions were supplied to ants in microcentrifuge tube caps and were refreshed every 3 days. To confirm the uptake of the ${ }^{13} \mathrm{C}$ 
isotope by ants fed on the ${ }^{13} \mathrm{C}$ labelled diet, a further 5 ants were fed on each type of glucose diet; these were submitted for isotope ratio mass spectrometry (IRMS) analysis, which enables the relative abundance of each stable isotope $\left({ }^{13} \mathrm{C}\right.$ and $\left.{ }^{12} \mathrm{C}\right)$ to be quantified in a sample.

\section{Isotope ratio mass spectrometry analysis}

The ${ }^{13} \mathrm{C}$ composition of ants fed on a ${ }^{13} \mathrm{C}$-labelled diet was determined by using a coupled Delta plus XP Isotope Ratio Mass Spectrometer/Flash HT Plus Elemental Analyser (Thermo Finnigan) in the University of East Anglia Analytical Facility. Ants were fed on a 5\% glucose solution (w/v) for 10 days; five ants were fed a ${ }^{13} \mathrm{C}$ glucose solution, and five were fed on a ${ }^{12} \mathrm{C}$ glucose solution. After 10 days, ants were washed once in $70 \%$ ETOH, then sequentially in sterile $\mathrm{dH}_{2} \mathrm{O}$ before drying on filter paper. The ants were then flash frozen and stored at $-80^{\circ} \mathrm{C}$ until being placed in a ScanVac Coolsafe freeze dryer for 5 days. Each ant was then put into an individual $75-\mu$ lin capsule (Elemental Microanalysis); capsules were loaded into an automatic sampler and completely converted to $\mathrm{CO}_{2}, \mathrm{~N}_{2}$ and $\mathrm{H}_{2} \mathrm{O}$ through combustion in an excess of oxygen (oxidation was carried out at $1020^{\circ} \mathrm{C}$, followed by reduction at $650^{\circ} \mathrm{C}$ ). Nitrous oxides formed during combustion were reduced using $\mathrm{Cu}$. Helium was used as a carrier gas. After passing through a water trap $\left(\mathrm{MgClO}_{4}\right)$, the gases were separated chromatographically on an isothermal GC column (Thermo PTFE, $0.8 \mathrm{~m}, 50^{\circ} \mathrm{C}$ ); the resulting peaks sequentially entered the ion source of the isotope ratio mass spectrometer. Gas species were then measured using a Faraday cup universal collector array, with masses of 44, 45, and 46 being monitored for the analysis of $\mathrm{CO}_{2}$. Casein and collagen were used to calibrate the system and normalise the data post-run; these standards have been calibrated against international certified standards and have an assigned $\delta^{13} \mathrm{C}$ value. Empty tin capsules were used as blanks. Each sample was analysed in triplicate. The ${ }^{13} \mathrm{C}$ content of samples was reported as the ${ }^{13} \mathrm{C}$ atom percent, which was calculated using the following formula: $\left({ }^{13} \mathrm{C} /{ }^{12} \mathrm{C}+{ }^{13} \mathrm{C}\right) \times 100$

\section{Fluorescent microscopy of ant feeding habits}

To confirm that the glucose water diet did not spread over the ant cuticle, a $20 \%$ glucose solution labelled with non-toxic fluorescent green drain tracing dye (Hydra) was fed to ants. Five mg ml${ }^{-1}$ of dye was added to a $20 \%$ glucose solution, of which $300 \mu \mathrm{l}$ was supplied to ants in the cap of an Eppendorf. Ants were sampled just after taking a feed, and after 6 and $24 \mathrm{~h}$ of being exposed to the dye, to trace the spread of the solution over time. After sampling, ants were carefully fixed on their backs, and brightfield and fluorescent images were acquired using a Zeiss M2 Bio Quad SV11 stereomicroscope
(Additional File 1: Fig. S2). The samples were illuminated either with a halogen lamp (brightfield) or a 100W Hg arc lamp (fluorescence) and reflected-light images were captured with an AxioCam HRc CCD camera and AxioVision software (Carl Zeiss, Cambridge, UK). Green fluorescence was excited with light passed through a $470-\mathrm{nm}$ filter ( $40 \mathrm{~nm}$ bandpass), and the emission was collected through a $525-\mathrm{nm}$ filter (50 $\mathrm{nm}$ bandpass).

\section{Cuticular dissection and RNA extraction}

At the end of the 10-day feeding experiment, the propleural plates of the propleura were removed from the ventral exoskeleton using a dissection microscope and fine sterile tweezers. Propleural plates from each of the 22 ants in each dietary group were placed together in lysis matrix E tubes (MP Biomedicals) on dry ice, before being snap-frozen in liquid nitrogen. A modified version of the Qiagen RNeasy Micro Kit protocol was used for all RNA extractions. Briefly, $700 \mu$ l of RLT buffer (with $1 \%$ beta mercaptoethanol) was added to each lysis matrix $\mathrm{E}$ tube before the samples could thaw. Tubes were then placed in a FastPrep-24 $5 \mathrm{G}$ benchtop homogeniser (MP Biomedicals) and disrupted for $40 \mathrm{~s}$ at $6 \mathrm{~m} / \mathrm{s}$. Samples were then centrifuged for $2 \mathrm{~min}$ at 13,000 rpm, and the supernatant was collected into a QIAshredder tube. This was centrifuged for $2 \mathrm{~min}$ at $13,000 \mathrm{rpm}$ to homogenise the lysate. The resulting flow-through was mixed vigorously with $700 \mu \mathrm{l}$ acidic phenol chloroform, then allowed to rest for $3 \mathrm{~min}$ at room temperature before centrifugation for $20 \mathrm{~min}$ at 13,000 rpm. The upper phase was then collected, and a $50 \%$ volume of $96 \%$ ethanol was added. The mixture was then placed into a MinElute column supplied with the Qiagen RNeasy Micro Kit. The kit protocol (including the on-column DNase I treatment) was then followed through to elution of the RNA, at which point $50 \mu \mathrm{l}$ of RNase free water (heated to $37^{\circ} \mathrm{C}$ ) was added to the column membrane and incubated at $37^{\circ} \mathrm{C}$ for $5 \mathrm{~min}$, before centrifuging for $1 \mathrm{~min}$ at 13,000 rpm to elute the RNA. To remove any remaining DNA, RNA was treated with the turbo DNase kit (Invitrogen): $5 \mu \mathrm{l}$ of $10 \times$ buffer and $2 \mu \mathrm{l}$ of Turbo DNase were added to $50 \mu \mathrm{l}$ of RNA and incubated at $37^{\circ} \mathrm{C}$ for $25 \mathrm{~min}$. RNA was then purified using the Qiagen Micro RNA Kit clean-up protocol. The quantity and purity of all RNA samples were checked using a nanodrop spectrophotometer and a Qubit $^{\mathrm{mm}}$ RNA HS assay kit (Invitrogen ${ }^{\mathrm{mm}}$ ).

\section{Density gradient ultracentrifugation and fractionation}

Density gradient ultracentrifugation was carried out to separate ${ }^{13} \mathrm{C}$ labelled ('heavy') from un-labelled ('light') RNA within the same sample. To make one complete gradient solution for the ultracentrifugation of one RNA sample, $4.5 \mathrm{ml}$ of caesium trifluoroacetate (CsTFA, $\sim 2 \mathrm{~g}$ $\mathrm{ml}^{-1}$, GE Healthcare, Munich, Germany) was added to 
$850 \mu \mathrm{l}$ of gradient buffer and $197.5 \mu \mathrm{l}$ formamide. Gradient buffer was made using an established protocol [83]. Following this, 270 ng of RNA from one replicate sample was added to the gradient solution, and the refractive index (R.I) of a $60 \mu \mathrm{l}$ aliquot was measured using a refractometer (Reichert Analytical Instruments, NY, USA). The R.I was then normalised to 1.3725 (approximately $1.79 \mathrm{~g} \mathrm{ml}^{-1}$ CsTFA). The samples underwent ultracentrifugation in a Beckman Optima XL-100K ultracentrifuge for $50 \mathrm{~h}$ at $20^{\circ} \mathrm{C}, 38,000 \mathrm{rpm}$ with a vacuum applied, using a Vti 65.2 rotar (Beckman Coulter, CA, USA). Deceleration occurred without brakes. Following centrifugation, samples were divided into 12 fractions using a peristaltic pump to gradually displace the gradient, according to an established protocol [44]. The R.I of fractions was measured to confirm the formation of a linear density gradient. RNA was precipitated from fractions by adding 1 volume of DEPC-treated sodium acetate $(1 \mathrm{M}$, $\mathrm{pH}$ 5.2), $1 \mu \mathrm{l}(20 \mu \mathrm{g})$ glycogen (from mussels, Sigma Aldrich), and 2 volumes of ice-cold $96 \%$ ethanol. Fractions were incubated overnight at $-20{ }^{\circ} \mathrm{C}$ then centrifuged for $30 \mathrm{~min}$ at $4{ }^{\circ} \mathrm{C}$ at $13,000 \times g$, before washing with $150 \mu \mathrm{l}$ of ice-cold $70 \%$ ethanol and centrifuging for a further $15 \mathrm{~min}$. Pellets were then airdried for $5 \mathrm{~min}$ and re-suspended in $15 \mu \mathrm{l}$ of nuclease-free water.

\section{Quantifying 165 rRNA gene copy number across RNA SIP fractions}

The RNA in each fraction was converted to cDNA by following the manufacturer's instructions for Superscript II (Invitrogen) with random hexamer primers (Invitrogen). 16S rRNA gene copy number was then quantified across cDNA fractions using qPCR. For this, $1 \mu \mathrm{l}$ of either template cDNA, standard DNA, or $\mathrm{dH}_{2} \mathrm{O}$ as a control, was added to $24 \mu \mathrm{l}$ of reaction mix containing 12.5 $\mu \mathrm{l}$ of $2 \times$ Sybr Green Jumpstart Taq Ready-mix (Sigma Aldrich), $0.125 \mu \mathrm{l}$ of each of the primers PRM341F and 518R (Additional File 1: Table S1), $4 \mu \mathrm{l}$ of $25 \mathrm{mM}$ $\mathrm{MgCl} 2,0.25 \mu \mathrm{l}$ of $20 \mu \mathrm{g} \mathrm{ll}^{-1}$ Bovine Serum Albumin (Sigma Aldrich), and $7 \mu \mathrm{l} \mathrm{dH}_{2} \mathrm{O}$. Sample cDNA, standards (a dilution series of the target 16S rRNA gene at known quantities), and negative controls were quantified in duplicate. Reactions were run under the following conditions: $95^{\circ} \mathrm{C}$ for $10 \mathrm{~min}$; 40 cycles of $95^{\circ} \mathrm{C}$ for $15 \mathrm{~s}$, $55^{\circ} \mathrm{C}$ for $30 \mathrm{~s}$, and $72{ }^{\circ} \mathrm{C}$ for $30 \mathrm{~s}$; plate read step at $83.5^{\circ} \mathrm{C}$ for $10 \mathrm{~s}$ (to avoid primer dimers); $96^{\circ} \mathrm{C}$ for $15 \mathrm{~s}$; 100 cycles at $55-95^{\circ} \mathrm{C}$ for $10 \mathrm{~s}$, ramping $0.5^{\circ} \mathrm{C}$ per cycle, followed by a plate read. Reactions were performed on 96-well plates (Bio-Rad). The threshold cycle (CT) for each sample was then converted to target molecule number by comparing to $\mathrm{CT}$ values of a dilution series of target DNA standards. These values were further converted to percentages based on the total number of 16S rRNA gene transcripts identified in each sample.

\section{Sequencing and analysis}

PCR was used to amplify the $16 \mathrm{~S}$ rRNA gene in each of the fractions that spanned the peaks in 16S rRNA gene copy number, identified via qPCR. This was done using the primers PRK341F and 518R (Additional file 1: Table S1). One unfractionated sample was also created for ants under each of the ${ }^{13} \mathrm{C}$ or ${ }^{12} \mathrm{C}$ dietary treatments, by pooling equal quantities of unfractionated cDNA from each of the 3 replicate groups and using this as a template for PCR amplification. The resulting PCR products were purified using the Qiagen MinElute ${ }^{\mathrm{Tm}}$ gel extraction kit and submitted for 16S rRNA gene amplicon sequencing using an Illumina MiSeq at MR DNA (Molecular Research LP), Shallowater, TX, USA. Sequence data was then processed by MR DNA using their established pipeline (as described in $[84,85]$ ). As part of this pipeline, paired-end sequences were merged, barcodes were trimmed, and sequences of less than $150 \mathrm{bp}$ and/or with ambiguous base calls were removed. The resulting sequences were denoised, and OTUs were assigned by clustering at $97 \%$ similarity. Chimeras were removed, and OTUs were taxonomically assigned using BLASTn against a curated database from GreenGenes, RDPII, and NCBI [86]. Plastid-like sequences were removed from the analysis. Upon receipt of the 16S rRNA gene sequencing data from MR DNA, OTU assignments were verified using QIIME2 and BLASTn, and statistical analysis was carried out using R 3.2.3[87]. OTUs assigned as Pseudonocardia were blasted against the 16S rRNA gene sequences for $P$. echinatior and $P$. octospinosus [32] to confirm the relative abundance of each of these vertically transmitted strains in the samples. All 16S rRNA gene amplicon sequencing data from this experiment has been deposited in the European Nucleotide Archive (ENA) public database under the study accession number PRJEB32900 [88]. Relative abundances were normalised using the qPCR data on the total 16S rRNA gene transcripts occurring within a fraction. Specifically, the following formula was used: $(R \times P) / 100$, where $R$ is the relative abundance of a taxon and $P$ is the percentage of $16 \mathrm{~S}$ rRNA gene transcripts detected in that particular fraction of a sample.

\section{Detecting the expression of Pseudonocardia BGCs in situ RNA extraction and sequencing from ant propleural plate samples}

The propleural plates of Acromyrmex echinatior ants were dissected (as described above) from individual mature worker ants that had a visible growth of Pseudonocardia bacteria on their cuticle. A pool of 80 ant cuticles was sampled from each of the colonies Ae1083 and 
Ae088, respectively (Additional file 1: Table S1), after which RNA was extracted as described above. The quantity, purity, and integrity of all RNA samples were checked using a nanodrop spectrophotometer and Qubit $^{\mathrm{Tm}}$ RNA HS assay kit (Invitrogen ${ }^{\mathrm{Tm}}$ ), as well an Experion $^{\text {TM }}$ bioanalyser with a prokaryotic RNA standard sensitivity analysis kit (Bio-Rad, California, USA). One microgram of RNA from each of the propleural plate samples was sent to Vertis Biotechnologie AG (FreisingWeihenstephan, Germany) where samples were processed and sequenced using an RNA sequencing approach [as described in [89]. Single-end sequencing (75 bp) was performed using an Illumina NextSeq500 platform. All sequencing reads have been deposited in the ENA public database under the study accession number PRJEB32903 [90].

\section{Processing of reads generated from RNA sequencing experiments}

The quality of Illumina sequences (returned from Vertis Biotechnologie AG) was assessed using the program FastQC (Babraham Institute, Cambridge, UK), before using TrimGalore version 0.4.5 (Babraham Institute, Cambridge, UK) to trim Illumina adaptors and lowquality base calls from the $3^{\prime}$ end of reads (an average quality phred score of 20 was used as cut-off). After trimming, sequences shorter than 20 base pairs were discarded. Trimmed files were then aligned to the reference genome for Acromyrmex echinatior (Additional File 1: Table S1 [55]) and the appropriate Pseudonocardia genome (either Ae707 for the sample from colony Ae1083, or Ae706 for the sample from colony Ae088 [32]; see Additional File 1: Table S1 for genome information). All alignments were done using the splice-aware alignment program HiSat2 [91] with the default settings. For each cuticular sample, reads that had mapped successfully to their respective Pseudonocardia genomes (Additional File 1: Table S2) were then mapped back to the ant genome (and vice versa) to check that reads did not crossmap between the two genomes (i.e. that they were either uniquely ant or bacterial reads)-reads that did not cross-map were retained for downstream analysis. Following alignment, the program HTSeq [92] was used to count mapped reads per annotated coding sequence (CDS) using the General Feature Format (GFF) file containing the annotated gene coordinates for each reference genome. Reads that mapped to multiple locations within a genome were discarded at this point, and only uniquely mapped reads were used in the counting process. Read counts per CDS were then converted to reads per kilobase of exon model per million reads (RPKM) by extracting the gene lengths from the GFF file. Converting reads to RPKM values normalises counts for RNA length and for the differences in sequencing depth, which enables more accurate comparisons both within and between samples [93].

\section{Expression analysis}

In order to investigate the expression levels of different functional groups of genes, protein sequences of every annotated gene in each Pseudonocardia genome [32] (Additional file 1: Table S1) were extracted and uploaded to BlastKOALA [94]. Assigned $K$ numbers were classified into five main KEGG pathway categories (and their associated sub-categories) using the KEGG Pathway Mapper tool. Each gene, with its associated $K$ number and category assignments, was then matched to its RPKM value from the RNA sequencing dataset so that the expression levels of different $\mathrm{KO}$ categories could be established. To investigate the expression of biosynthetic gene clusters (BGCs) by Pseudonocardia on the ant cuticle, reference genome sequences for $P$. octospinosus and $P$. echinatior (Additional file 1: Table S1 [32]) were uploaded to antiSMASH version 4.0, which predicts the presence and genomic location of BGCs based on sequence homology to known clusters [95]. RPKM values were then generated for each predicted $\mathrm{BGC}$, based on the length of the predicted cluster and read counts for genes situated within it.

\section{Isolation of Pseudonocardia and Escovopsis bioassays}

The Pseudonocardia strains PS1083 and PS088 (Additional file 1: Table S1) were isolated from the propleural plates of individual large Acromyrmex echinatior workers taken from colonies Ae1083 and Ae088 (colonies used in RNA-seq experiments, see Additional file 1: Table S1), respectively. Similarly, Pseudonocardia strains Ae322, Ae712, Ae280, Ae160, Ae703, Ae702, Ae707, Ae704, and Ae715 were isolated from large worker ants from colonies with the same labels maintained at the University of Copenhagen (these strains were only used for the growth rate experiments described in the section below). A sterile needle was used to scrape bacterial material off the propleural plates on the ventral part of the thorax; this was then streaked over Soya Flour Mannitol (SFM, Additional File 1: Table S4) agar plates and incubated at $30{ }^{\circ} \mathrm{C}$. The resulting colonies resembling Pseudonocardia were purified by repeatedly streaking single colonies onto SFM agar plates. Spore stocks were created using an established protocol [96]. The taxonomic identity of each Pseudonocardia isolate was confirmed via colony PCR and $16 \mathrm{~S}$ rRNA sequencing, as described in Holmes et al. [32]. Each resulting sequence was also aligned to both the Pseudonocardia octospinosus and Pseudonocardia echinatior 16S rRNA gene sequences [32] to reveal their percentage identities to each of the two species. 
Antifungal bioassays were carried out using the specialised fungal pathogen Escovopsis weberi strain CBS 810.71, acquired from the Westerdijk Fungal Biodiversity Institute (Additional File 1: Table S1). E. weberi was actively maintained on potato glucose agar (PGA, Additional File 1: Table S4) at room temperature. Fungal mycelia were transferred to a fresh plate every month. For bioassays, a plug of actively growing mycelium was transferred from PGA plates to the edge of a Glucose Yeast Malt (GYM, Additional File 1: Table S4) agar plate with a growing Pseudonocardia colony (strain PS1083 or PS088, Additional File 1: Table S1), using the end of a sterile glass Pasteur pipette. Plates were then left at room temperature for 2 weeks. A zone of clearing around the Pseudonocardia colony indicated the presence of antifungal activity. Three replicate experiments (with three replicate bioassay plates per Pseudonocardia strain) were carried out, whereby different $E$. weberi starter plates were used as an inoculum.

\section{In vitro competition experiments \\ Collection and isolation of bacterial strains}

Nineteen strains of Pseudonocardia (11 strains of $P$. echinatior and 8 of Pseudonocardia octospinosus, Additional file 1: Table S1) were isolated from the cuticles of individual Acromyrmex echinatior worker ants across 18 different colonies and genotypes, as described above. Ten of these isolated Pseudonocardia strains were previously genome-sequenced by Holmes et al. [32]. The 10 environmental antibiotic-producer strains (all in the genus Streptomyces) were taken from general collections in the Hutchings lab and are a mixture of isolates from either soil environments or from worker ants taken from captive colonies (Additional file 1: Table S1). The 10 environmental non-producer strains were obtained from the Hutchings lab (two strains) and from the ESKAPE suite (eight strains with varying origins (human skin, soil, etc.)) used to test antibiotic resistance or efficacy in clinical/research settings (Additional file 1: Table S1).

\section{Individual growth rate experiments}

To create the Pseudonocardia-infused media, lawns of each of the 19 isolates (Additional File 1: Table S1) were grown, by plating $30 \mu \mathrm{l}$ of spores (in $20 \%$ glycerol) onto $90 \mathrm{~mm}$ SFM agar plates (Additional File 1: Table S4). The control plates were inoculated with $20 \%$ glycerol only. We incubated these plates at $30^{\circ} \mathrm{C}$ for 6 weeks, which ultimately produced confluent lawns from 17 strains that could be included in the experiments (6 Ps1, 11 Ps2). After a 6-week incubation period, the agar medium was flipped to reveal a new surface for colonisation. The 10 environmental producer strains and the 10 environmental non-producer strains (Additional File 1: Table S1) were then inoculated onto the plates to compare their growth rates on each type of media. Each of the plates received 10 evenly spaced colonies, with 3 replicates, generating 2 invader types $\times 17$ Ps-mediatypes $\times 3$ replicates $=102$ Ps-infused plates, and 2 invader types $\times 3$ replicates $=6$ control plates, for 1020 treatment and 60 control inoculations. Each strain inoculation used $5 \mu \mathrm{l}$ of solution (approx. $1 \times 10^{6}$ cells per $\mathrm{ml}$ in $20 \%$ glycerol), spotted at evenly spaced positions and without coming into direct contact. All plates were incubated at $30^{\circ} \mathrm{C}$ for 5 days, after which photographs were taken.

Images were processed in the Fiji software [97, 98], creating binary negatives (black and white) so automated tools could identify discrete areas of growth (black) and measure growth areas for each invading strain; in the few cases where binary image resolution was insufficient, outlines were added manually before area calculation. Forty-eight producer-inoculated and 57 non-producerinoculated treatment measurements were excluded because plate condition had deteriorated to become unscorable or they were contaminated, leaving final sample sizes of 1020-48-57 = 915 treatment inoculations and 60 controls.

The second growth rate experiment compared the 10 Acromyrmex-resident, non-producer strains with 9 of the environmental producer strains ( 1 of the 10 inoculations failed to grow). All 19 Pseudonocardia strains grew sufficiently to be included in this experiment, and each plate was again inoculated with 10 or 9 evenly spaced colonies. Starting sample sizes were therefore 2 invader types $\times 19$ Ps-media-types $\times 3$ replicates $=114$ Psinfused plates and $2 \times 3=6$ control plates, for 1083 treatment and 57 control inoculations. Fifty producer and 20 non-producer treatment measurements were excluded for the same reasons as above, leaving final sample sizes of 1083-50-20 = 1013 treatment and 57 control inoculations, scored as above.

\section{Pairwise competition experiment}

Experiments were set up to test whether antibioticproducer strains could win in direct competition against non-producing strains, both on normal media and on media infused with Pseudonocardia secondary metabolites. To create the Pseudonocardia-infused media, we plated $30 \mu \mathrm{l}$ of spores (in $20 \%$ glycerol) onto $50 \mathrm{~mm}$ SFM agar plates (Additional File 1: Table S4). The control plates were inoculated with $20 \%(\mathrm{v} / \mathrm{v})$ glycerol only. We incubated these plates at $30{ }^{\circ} \mathrm{C}$ for 6 weeks, which ultimately produced confluent lawns. As above, the agar was flipped to reveal a surface open for colonisation. Environmental producers and non-producers were then coinoculated onto these media (as well as on control media with no Pseudonocardia present), and we measured the outcome of competition as a win, loss, or 
draw. To keep the number of tests manageable, we used two combinations of Pseudonocardia-infused media and Streptomyces: Pseudonocardia octospinosus (strain Ae707-CP-A2) + Streptomyces S8, and Pseudonocardia echinatior (strain Ae717) + Streptomyces S2 (Additional File 1: Table S1). We competed the two Streptomyces strains (S2, S8) against the 10 environmental nonproducer strains (20 pairings). Each Strepromyces strain was prepared as $10^{6}$ spores $\mathrm{ml}^{-1}$ in $20 \%$ glycerol. Each non-producer strains was grown overnight in $10 \mathrm{ml}$ of Lennox broth (Additional File 1: Table S4), before subculturing (1:100 dilution) into $10 \mathrm{ml}$ of fresh Lennox, and incubating at $37^{\circ} \mathrm{C}$ for $3-4 \mathrm{~h}$. The $\mathrm{OD}_{600}$ was then measured, assuming that an $\mathrm{OD}_{600}$ of 1 represented $8 \times$ $10^{9}$ cells. Similar dilutions of $10^{6}$ cells per $\mathrm{ml}$ were made for each non-producer strain in 20\% (v/v) glycerol, after which producer and non-producer preparations were mixed at a ratio of $1: 1(\mathrm{v} / \mathrm{v})$ and co-inoculated as a mixture of $20 \mu \mathrm{l}\left(10^{4}\right.$ spore-cells of each) on the designated Pseudonocardia-infused media with 5 replicates per pairing. We used 150 plates for the S8 experiment (including 100 control plates; 10 replicates per pairing) and 100 plates for the $\mathrm{S} 2$ experiment (including 50 control plates; 5 replicates per pairing). Plates were incubated at $30^{\circ} \mathrm{C}$ for 5 days before imaging, after which images were scored with respect to the producer as win (dominant growth), draw (both strains growing with no clear dominant), or lose (little or no visible growth), always with reference to images of each strain grown alone on control medium to minimise observer bias. One plate's outcome was too ambiguous to score and was discarded. All plates were independently scored by two observers, one using photos of the original images, which produced datasets giving the same statistical results. We report the direct observer's scores. For analysis, draw outcomes were omitted, and a general linear mixed-effects model, including non-antibiotic-producer strain as a random intercept (10 groups), was used to test for an effect of the medium term (control vs. Ps1/2-infused) on competitive outcome (win vs. loss) ((lme4::glmer (outcome medium $+(1 \mid$ non.producer.strain $)$, family = binomial $)$. Significance was estimated using term deletion.

\section{Antibiotic resistance assays}

The key assumption of screening theory is that antibiotic-producers are better at resisting antibiotics, as measured by growth rates in the presence of antibiotics, because this correlation is what allows producer strains to better endure the demanding environment produced by Pseudonocardia. We tested this assumption by growing the 10 environmental producer strains, the 10 environmental non-producer strains, and the 10 resident non-producers strains (Additional File 1: Table S1) in the presence of 8 different antibiotics (Additional File 1:
Table S4), representing a range of chemical classes and modes of action. Antibiotics were added to $1 \mathrm{ml}$ of LBLennox/SFM medium (Additional File 1: Table S4) in a 24-well microtitre plate at 6 different concentrations. The relative concentration range was the same for each antibiotic, although actual concentrations reflected activity (Additional File 1: Table S4). Producers and nonproducers were inoculated onto plates and incubated at $30^{\circ} \mathrm{C}$ for 7 days, then photographed. The lowest effective concentration (LEC, lowest concentration with inhibitory effect) and minimum inhibitory concentration (MIC, lowest concentration with no growth) scores were assigned on a Likert scale of $1-6$, where 1 was no resistance and 6 was resistance above the concentrations tested (adapted from generalised MIC methods; reviewed by Balouiri et al. [64]).

\section{Statistical analyses}

$\mathrm{R}$ markdown-format scripts, input datafiles, and html output files for the analyses in the main text Figures 4, 5, and 6 and in Figures S9 and S10 (Additional File 1) are provided as a single $\mathrm{R}$ project folder at github.com/ dougwyu/Worsley_et_al_screening_test_R_code [99]

\section{Supplementary Information}

The online version contains supplementary material available at https://doi. org/10.1186/s12915-021-01142-w.

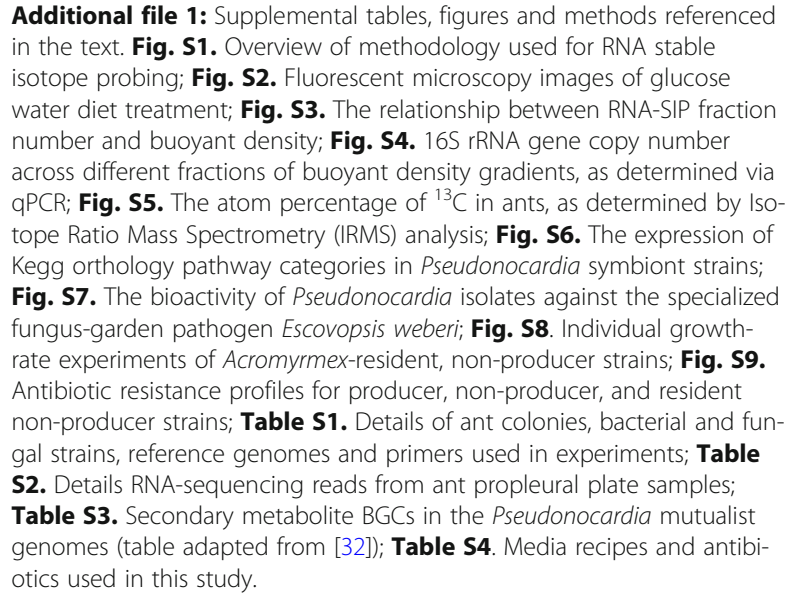

Additional file 1: Supplemental tables, figures and methods referenced in the text. Fig. S1. Overview of methodology used for RNA stable isotope probing; Fig. S2. Fluorescent microscopy images of glucose water diet treatment; Fig. S3. The relationship between RNA-SIP fraction number and buoyant density; Fig. S4. 16S rRNA gene copy number across different fractions of buoyant density gradients, as determined via qPCR; Fig. S5. The atom percentage of ${ }^{13} \mathrm{C}$ in ants, as determined by Isotope Ratio Mass Spectrometry (IRMS) analysis; Fig. S6. The expression of Kegg orthology pathway categories in Pseudonocardia symbiont strains; Fig. S7. The bioactivity of Pseudonocardia isolates against the specialized fungus-garden pathogen Escovopsis weberi; Fig. S8. Individual growthrate experiments of Acromyrmex-resident, non-producer strains; Fig. S9. Antibiotic resistance profiles for producer, non-producer, and resident non-producer strains; Table S1. Details of ant colonies, bacterial and fungal strains, reference genomes and primers used in experiments; Table S2. Details RNA-sequencing reads from ant propleural plate samples; Table S3. Secondary metabolite BGCs in the Pseudonocardia mutualist genomes (table adapted from [32]); Table S4. Media recipes and antibiotics used in this study.

\section{Acknowledgements}

We thank the Smithsonian Tropical Research Institute for the logistical help and facilities for all work in Gamboa, Panama, and the Autoridad Nacional del Ambiente y el Mar for permission to sample and export ants to Copenhagen. We thank Simon Moxon for the advice on RNA sequencing analysis, Paul Disdle for his assistentance with the IRMS analysis, and Elaine Patrick and Sylvia Matthiesen for the lab and logistics support.

\section{Authors' contributions}

SFW, TMI, NAH, MMA-B, MS, BW, JCM, JJB, DWY, and MIH designed the research. SFW, TI, NAH, JJB, DWY, and MIH wrote the manuscript with comments from all other authors. SFW performed the RNA sequencing and RNA stable isotope probing experiments and maintained the captive ant colonies at UEA. TI, NAH, $M M A B$, and MS cultured the bacteria from the ants and performed the in vitro 
bioassays. SFW and DWY performed the statistical analysis. All authors read and approved the final manuscript.

\section{Funding}

This work was supported by a NERC PhD studentship to SFW (NERC Doctoral Training Programme grant NE/L002582/1); NERC grants NE/J01074X/1 to MIH and DWY; NE/M015033/1 and NE/M014657/1 to MIH, JCM, DWY, and BW; European Research Council Advanced grant 323085 to JJB; and Marie Curie Individual European Fellowship grant 627949 to TI. DWY was also supported by the Key Research Program of Frontier Sciences, Chinese Academy of Sciences (QYZDY-SSW-SMC024), and the Strategic Priority Research Program, Chinese Academy of Sciences (XDA20050202, XDB31000000).

\section{Availability of data and materials}

The $16 \mathrm{~S}$ rRNA gene amplicon sequencing data from the SIP experiment, as well as the RNA sequencing data, have been uploaded to the European Nucleotide Archive (ENA), under the accession numbers PRJEB32900 [88] and PRJEB32903 [90], respectively. R markdown-format scripts, input datafiles, and html output files for the analyses in the main text Figs. 4, 5, and 6 and in Additional file 1: Fig. S8 \& S9 are also provided as a single $\mathrm{R}$ project folder at github.com/dougwyu/Worsley_et_al_screening_test_R_code [99].

\section{Declarations}

\section{Ethics approval and consent to participate}

Not applicable

\section{Consent for publication}

Not applicable

\section{Competing interests}

The authors declare that they have no competing interests.

\section{Author details}

${ }^{1}$ School of Biological Sciences, Norwich Research Park, University of East Anglia, Norwich, Norfolk NR4 7TJ, UK. ${ }^{2}$ Centre for Social Evolution, Section for Ecology and Evolution, Department of Biology, University of Copenhagen, Copenhagen, Denmark. ${ }^{3}$ Department of Molecular Microbiology, John Innes Centre, Norwich Research Park, Norwich, Norfolk NR4 7UH, UK. ${ }^{4}$ School of Environmental Sciences, Norwich Research Park, University of East Anglia, Norwich, Norfolk NR4 7TJ, UK. ${ }^{5}$ State Key Laboratory of Genetic Resources and Evolution, Kunming Institute of Zoology, Chinese Academy of Sciences, Kunming 650223, Yunnan, China. ${ }^{6}$ Center for Excellence in Animal Evolution and Genetics, Chinese Academy of Sciences, Kunming 650223, Yunnan, China

Received: 7 May 2021 Accepted: 3 September 202

Published online: 15 September 2021

\section{References}

1. McCutcheon JP, Boyd BM, Dale C. The life of an insect endosymbiont from the cradle to the grave. Curr Biol. 2019;29(11):R485-R95. https://doi.org/10.1 016/j.cub.2019.03.032.

2. Brucker RM, Bordenstein SR. The hologenomic basis of speciation: gut bacteria cause hybrid lethality in the genus Nasonia. Science. 2013; 341(6146):667-9. https://doi.org/10.1126/science.1240659.

3. Andersen SB, Yek SH, Nash DR, Boomsma JJ. Interaction specificity between leaf-cutting ants and vertically transmitted Pseudonocardia bacteria. BMC Evol Biol. 2015;15(1):1. https://doi.org/10.1186/s12862-015-0308-2.

4. Kaltenpoth M, Göttler W, Herzner G, Strohm E. Symbiotic bacteria protect wasp larvae from fungal infestation. Curr Biol. 2005;15(5):475-9. https://doi org/10.1016/j.cub.2004.12.084.

5. Engel P, Moran NA. The gut microbiota of insects - diversity in structure and function. FEMS Microbiol Rev. 2013;37(5):699-735. https://doi.org/10.1111/1 574-6976.12025

6. Brune A. Symbiotic digestion of lignocellulose in termite guts. Nat Rev Microbiol. 2014;12(3):168-80. https://doi.org/10.1038/nrmicro3182.

7. Granato ET, Meiller-Legrand TA, Foster KR. The evolution and ecology of bacterial warfare. Curr Biol. 2019;29(11):R521-R37. https://doi.org/10.1016/j. cub.2019.04.024
8. Foster KR, Schluter J, Coyte KZ, Rakoff-Nahoum S. The evolution of the host microbiome as an ecosystem on a leash. Nature. 2017;548(7665):43-51. https://doi.org/10.1038/nature23292.

9. Widder S, Allen RJ, Pfeiffer T, Curtis TP, Wiuf C, Sloan WT, et al. Challenges in microbial ecology: building predictive understanding of community function and dynamics. ISME J. 2016;10(11):2557-68. https://doi.org/10.1038/ ismej.2016.45

10. Hoye BJ, Fenton A. Animal host-microbe interactions. J Anim Ecol. 2018; 87(2):315-9. https://doi.org/10.1111/1365-2656.12788.

11. Archetti M, Ubeda F, Fudenberg D, Green J, Pierce NE, Yu DW. Let the right one in: a microeconomic approach to partner choice in mutualisms. Am Nat. 2011;177(1):75-85. https://doi.org/10.1086/657622.

12. Scheuring I, Yu DW. How to assemble a beneficial microbiome in three easy steps. Ecol Lett. 2012;15(11):1300-7. https://doi.org/10.1111/j.1461-0248.2012 01853.x

13. Boza G, Worsley SF, Yu DW, Scheuring I. Efficient assembly and long-term stability of defensive microbiomes via private resources and community bistability. Plos Comput Biol. 2019;15(5):e1007109. https://doi.org/10.1371/ journal.pcbi.1007109.

14. Heil M. Let the best one stay: screening of ant defenders by Acacia host plants functions independently of partner choice or host sanctions. J Ecol. 2013;101(3):684-8. https://doi.org/10.1111/1365-2745.12060.

15. Tragust S, Herrmann C, Häfner J, Braasch R, Tilgen C, Hoock M, et al. Formicine ants swallow their highly acidic poison for gut microbial selection and control. eLife. 2020;9:e60287. https://doi.org/10.7554/eLife.60287.

16. Itoh H, Jang S, Takeshita K, Ohbayashi T, Ohnishi N, Meng XY, et al. Hostsymbiont specificity determined by microbe-microbe competition in an insect gut. Proc Natl Acad Sci U S A. 2019;116(45):22673-82. https://doi. org/10.1073/pnas.1912397116.

17. Ranger CM, Biedermann PHW, Phuntumart V, Beligala GU, Ghosh S, Palmquist DE, et al. Symbiont selection via alcohol benefits fungus farming by ambrosia beetles. Proc Natl Acad Sci U S A. 2018;115(17):4447-52. https://doi.org/10.1073/pnas.1716852115.

18. Andersen SB, Hansen LH, Sapountzis P, Sorensen SJ, Boomsma JJ. Specificity and stability of the Acromyrmex-Pseudonocardia symbiosis. Mol Ecol. 2013; 22(16):4307-21. https://doi.org/10.1111/mec.12380.

19. Chapela IH, Rehner SA, Schultz TR, Mueller UG. Evolutionary history of the symbiosis between fungus-growing ants and their fungi. Science. 1994; 266(5191):1691-4. https://doi.org/10.1126/science.266.5191.1691.

20. Mueller UG, Rehner SA, Schultz TR. The evolution of agriculture in ants. Science. 1998;281(5385):2034-8. https://doi.org/10.1126/science.281.5385.2 034.

21. Currie CR. A community of ants, fungi, and bacteria: a multilateral approach to studying symbiosis. Annu Rev Microbiol. 2001;55(1):357-80. https://doi. org/10.1146/annurev.micro.55.1.357.

22. De Fine Licht HH, Boomsma JJ, Tunlid A. Symbiotic adaptations in the fungal cultivar of leaf-cutting ants. Nat Commun. 2014;5(1):5675. https://doi. org/10.1038/ncomms6675

23. Sapountzis P, Zhukova M, Shik JZ, Schiott M, Boomsma JJ. Reconstructing the functions of endosymbiotic Mollicutes in fungus-growing ants. Elife. 2018;7. https://doi.org/10.7554/eLife.39209.

24. Reynolds HT, Currie CR. Pathogenicity of Escovopsis weberi: the parasite of the attine ant-microbe symbiosis directly consumes the ant-cultivated fungus. Mycologia. 2004;96(5):955-9. https://doi.org/10.1080/15572536.2 005.11832895

25. Heine D, Holmes NA, Worsley SF, Santos ACA, Innocent TM, Scherlach K, et al. Chemical warfare between leafcutter ant symbionts and a co-evolved pathogen. Nat Commun. 2018;9(1):2208. https://doi.org/10.1038/s41467-01804520-1.

26. Worsley SF, Innocent TM, Heine D, Murrell JC, Yu DW, Wilkinson B, et al. Symbiotic partnerships and their chemical interactions in the leafcutter ants (Hymenoptera: Formicidae). Myrmecol News. 2018;27:59-74.

27. de Man TJ, Stajich JE, Kubicek CP, Teiling C, Chenthamara K, Atanasova L, et al. Small genome of the fungus Escovopsis weberi, a specialized disease agent of ant agriculture. Proc Natl Acad Sci U S A. 2016;113(13):3567-72. https://doi.org/10.1073/pnas.1518501113.

28. Currie CR, Stuart AE. Weeding and grooming of pathogens in agriculture by ants. Proc Biol Sci. 2001;268(1471):1033-9. https://doi.org/10.1098/rspb.2 001.1605

29. Fernandez-Marin H, Nash DR, Higginbotham S, Estrada C, van Zweden JS, d'Ettorre $P$, et al. Functional role of phenylacetic acid from metapleural 
gland secretions in controlling fungal pathogens in evolutionarily derived leaf-cutting ants. Proc Biol Sci. 2015;282(1807):20150212. https://doi.org/10.1 098/rspb.2015.0212.

30. Fernandez-Marin H, Zimmerman JK, Rehner SA, Wcislo WT. Active use of the metapleural glands by ants in controlling fungal infection. Proc Biol Sci. 2006;273(1594):1689-95. https://doi.org/10.1098/rspb.2006.3492.

31. Currie CR, Scott JA, Summerbell RC, Malloch D. Fungus-growing ants use antibiotic-producing bacteria to control garden parasites. Nature. 1999; 398(6729):701-4. https://doi.org/10.1038/19519.

32. Holmes NA, Innocent TM, Heine D, Bassam MA, Worsley SF, Trottmann F, et al. Genome analysis of two Pseudonocardia phylotypes associated with Acromyrmex leafcutter ants reveals their biosynthetic potential. Front Microbiol. 2016;7:2073. https://doi.org/10.3389/fmicb.2016.02073.

33. Poulsen M, Cafaro M, Boomsma JJ, Currie CR. Specificity of the mutualistic association between actinomycete bacteria and two sympatric species of Acromyrmex leaf-cutting ants. Mol Ecol. 2005;14(11):3597-604. https://doi. org/10.1111/j.1365-294X.2005.02695.x.

34. Marsh SE, Poulsen M, Pinto-Tomás A, Currie CR. Interaction between workers during a short time window is required for bacterial symbiont transmission in Acromyrmex leaf-cutting ants. PLoS One. 2014;9(7):e103269. https://doi.org/10.1371/journal.pone.0103269.

35. Poulsen M, Bot ANM, Currie CR, Nielsen MG, Boomsma JJ. Within-colony transmission and the cost of a mutualistic bacterium in the leaf-cutting ant Acromyrmex octospinosus. Funct Ecol. 2003;17(2):260-9. https://doi.org/10.1 046/j.1365-2435.2003.00726.x.

36. Kost C, Lakatos T, Böttcher I, Arendholz W-R, Redenbach M, Wirth R. Nonspecific association between filamentous bacteria and fungus-growing ants. Naturwissenschaften. 2007;94(10):821-8. https://doi.org/10.1007/s00114-0070262-y.

37. Barke J, Seipke RF, Gruschow S, Heavens D, Drou N, Bibb MJ, et al. A mixed community of actinomycetes produce multiple antibiotics for the fungus farming ant Acromyrmex octospinosus. BMC Biol. 2010;8(1). https://doi.org/1 0.1186/1741-7007-8-109.

38. Haeder S, Wirth R, Herz H, Spiteller D. Candicidin-producing Streptomyces support leaf-cutting ants to protect their fungus garden against the pathogenic fungus Escovopsis. Proc Natl Acad Sci USA. 2009;106(12):4742-6. https://doi.org/10.1073/pnas.0812082106.

39. Schoenian I, Spiteller M, Ghaste M, Wirth R, Herz H, Spiteller D. Chemical basis of the synergism and antagonism in microbial communities in the nests of leaf-cutting ants. Proc Natl Acad Sci U S A. 2011;108(5):1955-60. https://doi.org/10.1073/pnas.1008441108.

40. Sen R, Ishak HD, Estrada D, Dowd SE, Hong E, Mueller UG. Generalized antifungal activity and 454-screening of Pseudonocardia and Amycolatopsis bacteria in nests of fungus-growing ants. Proc Natl Acad Sci USA. 2009; 106(42):17805-10. https://doi.org/10.1073/pnas.0904827106.

41. Currie CR, Poulsen M, Mendenhall J, Boomsma JJ, Billen J. Coevolved crypts and exocrine glands support mutualistic bacteria in fungus-growing ants. Science. 2006;311(5757):81-3. https://doi.org/10.1126/science.1119744.

42. Dumont $M G$, Murrell JC. Stable isotope probing - linking microbial identity to function. Nat Rev Microbiol. 2005;3(6):499-504. https://doi.org/10.1038/ nrmicro1162.

43. Neufeld JD, Wagner M, Murrell JC. Who eats what, where and when? Isotope-labelling experiments are coming of age. ISME J. 2007;1(2):103-10. https://doi.org/10.1038/ismej.2007.30.

44. Whiteley AS, Thomson B, Lueders T, Manefield M. RNA stable-isotope probing. Nat Protoc. 2007;2(4):838-44. https://doi.org/10.1038/nprot.2007.115.

45. Andersen SB, Boye M, Nash DR, Boomsma JJ. Dynamic Wolbachia prevalence in Acromyrmex leaf-cutting ants: potential for a nutritional symbiosis. J Evol Biol. 2012;25(7):1340-50. https://doi.org/10.1111/j.1420-91 01.2012.02521.x

46. Sapountzis P, Nash DR, Schiott M, Boomsma JJ. The evolution of abdominal microbiomes in fungus-growing ants. Mol Ecol. 2019;28(4):879-99. https:// doi.org/10.1111/mec.14931

47. Seipke RF, Barke J, Brearley C, Hill L, Douglas WY, Goss RJ, et al. A single Streptomyces symbiont makes multiple antifungals to support the fungus farming ant Acromyrmex octospinosus. PLoS One. 2011;6(8):e22028. https:// doi.org/10.1371/journal.pone.0022028.

48. Gomez-Escribano JP, Bibb MJ. Engineering Streptomyces coelicolor for heterologous expression of secondary metabolite gene clusters. Microb Biotechnol. 2011:4(2):207-15. https://doi.org/10.1111/j.1751-7915.2010.00219.x
49. Hopwood DA, Kieser T, Wright HM, Bibb MJ. Plasmids, recombination and chromosome mapping in Streptomyces lividans 66. Microbiology. 1983; 129(7):2257-69. https://doi.org/10.1099/00221287-129-7-2257.

50. Bentley SD, Chater KF, Cerdeno-Tarraga AM, Challis GL, Thomson NR, James $\mathrm{KD}$, et al. Complete genome sequence of the model actinomycete Streptomyces coelicolor A3(2). Nature. 2002;417(6885):141-7. https://doi.org/1 $0.1038 / 417141 \mathrm{a}$

51. Bignell DR, Seipke RF, Huguet-Tapia JC, Chambers AH, Parry RJ, Loria R. Streptomyces scabies 87-22 contains a coronafacic acid-like biosynthetic cluster that contributes to plant-microbe interactions. Mol Plant Microbe Interact. 2010;23(2):161-75. https://doi.org/10.1094/MPMI-23-2-0161.

52. Seipke RF, Barke J, Heavens D, Yu DW, Hutchings MI. Analysis of the bacterial communities associated with two ant-plant symbioses. Microbiologyopen. 2013;2(2):276-83. https://doi.org/10.1002/mbo3.73.

53. Holmes NA, Devine R, Qin Z, Seipke RF, Wilkinson B, Hutchings MI. Complete genome sequence of Streptomyces formicae KY5, the formicamycin producer. J Biotechnol. 2018;265:116-8. https://doi.org/10.101 6/j.jbiotec.2017.11.011.

54. Seipke RF, Patrick $E_{1}$ Hutchings MI. Regulation of antimycin biosynthesis by the orphan ECF RNA polymerase sigma factor sigma (AntA.). PeerJ. 2014;2: e253.

55. Nygaard S, Zhang G, Schiott M, Li C, Wurm Y, Hu H, et al. The genome of the leaf-cutting ant Acromyrmex echinatior suggests key adaptations to advanced social life and fungus farming. Genome Res. 2011;21(8):1339-48. https://doi.org/10.1101/gr.121392.111.

56. Muyzer G, de Waal EC, Uitterlinden AG. Profiling of complex microbial populations by denaturing gradient gel electrophoresis analysis of polymerase chain reaction-amplified genes coding for $16 \mathrm{~S}$ rRNA. Appl Environ Microbiol. 1993;59(3):695-700. https://doi.org/10.1128/aem.59.3.695700.1993.

57. Gershenzon J, Dudareva N. The function of terpene natural products in the natural world. Nat Chem Biol. 2007;3(7):408-14. https://doi.org/10.1038/ nchembio.2007.5.

58. Richter TK, Hughes CC, Moore BS. Sioxanthin, a novel glycosylated carotenoid, reveals an unusual subclustered biosynthetic pathway. Environ Microbiol. 2015;17(6):2158-71. https://doi.org/10.1111/1462-2920.12669.

59. Nupur LN, Vats A, Dhanda SK, Raghava GP, Pinnaka AK, Kumar A. ProCarDB: a database of bacterial carotenoids. BMC Microbiol. 2016;16(1):96. https:// doi.org/10.1186/s12866-016-0715-6.

60. Chikindas ML, Weeks R, Drider D, Chistyakov VA, Dicks LM. Functions and emerging applications of bacteriocins. Curr Opin Biotechnol. 2018;49:23-8. https://doi.org/10.1016/j.copbio.2017.07.011.

61. Cotter PD, Ross RP, Hill C. Bacteriocins - a viable alternative to antibiotics? Nat Rev Microbiol. 2013;11(2):95-105. https://doi.org/10.1038/nrmicro2937.

62. Riley MA, Gordon DM. The ecological role of bacteriocins in bacterial competition. Trends Microbiol. 1999;7(3):129-33. https://doi.org/10.1016/ S0966-842X(99)01459-6.

63. Algburi A, Zehm S, Netrebov V, Bren AB, Chistyakov V, Chikindas ML. Subtilosin prevents biofilm formation by inhibiting bacterial quorum sensing. Probiotics Antimicrob Proteins. 2017;9(1):81-90. https://doi.org/10.1 007/s12602-016-9242-x.

64. Balouiri M, Sadiki M, Ibnsouda SK. Methods for in vitro evaluating antimicrobial activity: a review. J Pharm Anal. 2016;6(2):71-9. https://doi. org/10.1016/j.jpha.2015.11.005.

65. Currie C, Bot A, Boomsma JJ. Experimental evidence of a tripartite mutualism: bacteria protect ant fungus gardens from specialized parasites. Oikos. 2003;101(1):91-102. https://doi.org/10.1034/j.1600-0706.2003.12036.x.

66. Oldroyd GE. Speak, friend, and enter: signalling systems that promote beneficial symbiotic associations in plants. Nat Rev Microbiol. 2013;11(4): 252-63. https://doi.org/10.1038/nrmicro2990.

67. Archetti M, Miller JB, Yu DW. Evolution of passwords for cost-free honest signalling between symbionts and hosts. bioRxiv. 2016:065755.

68. McLaren MR, Willis AD, Callahan BJ. Consistent and correctable bias in metagenomic sequencing experiments. Elife. 2019;8. https://doi.org/10. 7554/eLife.46923.

69. Williamson BD, Hughes JP, Willis AD. A multiview model for relative and absolute microbial abundances. Biometrics. 2021;1-14. https://doi.org/1 0.1111/biom.13503.

70. Poulsen M, Bot AN, Boomsma JJ. The effect of metapleural gland secretion on the growth of a mutualistic bacterium on the cuticle of leaf-cutting ants. 
Naturwissenschaften. 2003;90(9):406-9. https://doi.org/10.1007/s00114-0030450-3.

71. Musat N, Musat F, Weber PK, Pett-Ridge J. Tracking microbial interactions with NanoSIMS. Curr Opin Biotechnol. 2016;41:114-21. https://doi.org/10.101 6/j.copbio.2016.06.007.

72. Berry D, Stecher B, Schintlmeister A, Reichert J, Brugiroux S, Wild B, et al. Host-compound foraging by intestinal microbiota revealed by single-cell stable isotope probing. Proc Natl Acad Sci U S A. 2013;110(12):4720-5. https://doi.org/10.1073/pnas.1219247110.

73. Wang $Y$, Huang WE, Cui L, Wagner M. Single cell stable isotope probing in microbiology using Raman microspectroscopy. Curr Opin Biotechnol. 2016 41:34-42. https://doi.org/10.1016/j.copbio.2016.04.018.

74. Bertrand S, Bohni N, Schnee S, Schumpp O, Gindro K, Wolfender JL. Metabolite induction via microorganism co-culture: a potential way to enhance chemical diversity for drug discovery. Biotechnol Adv. 2014;32(6): 1180-204. https://doi.org/10.1016/j.biotechadv.2014.03.001.

75. Lee N, Kim W, Chung J, Lee Y, Cho S, Jang KS, et al. Iron competition triggers antibiotic biosynthesis in Streptomyces coelicolor during coculture with Myxococcus xanthus. ISME J. 2020;14(5):1111-24. https://doi.org/10.103 8/541396-020-0594-6 .

76. Zivkovic AM, German JB, Lebrilla CB, Mills DA. Human milk glycobiome and its impact on the infant gastrointestinal microbiota. Proc Natl Acad Sci U S A. 2011;108(Suppl 1):4653-8. https://doi.org/10.1073/pnas.1000083107.

77. Brinker P, Weig A, Rambold G, Feldhaar H, Tragust S. Microbial community composition of nest-carton and adjoining soil of the ant Lasius fuliginosus and the role of host secretions in structuring microbial communities. Fungal Ecol. 2019;38:44-53. https://doi.org/10.1016/j.funeco.2018.08.007

78. Carlstrom Cl, Field CM, Bortfeld-Miller M, Muller B, Sunagawa S, Vorholt JA. Synthetic microbiota reveal priority effects and keystone strains in the Arabidopsis phyllosphere. Nat Ecol Evol. 2019;3(10):1445-54. https://doi.org/1 0.1038/s41559-019-0994-z.

79. Cai T, Cai W, Zhang J, Zheng H, Tsou AM, Xiao L, et al. Host legume-exuded antimetabolites optimize the symbiotic rhizosphere. Mol Microbiol. 2009; 73(3):507-17. https://doi.org/10.1111/j.1365-2958.2009.06790.x.

80. Neal AL, Ahmad S, Gordon-Weeks R, Ton J. Benzoxazinoids in root exudates of maize attract Pseudomonas putida to the rhizosphere. PLoS One. 2012; 7(4):e35498. https://doi.org/10.1371/journal.pone.0035498.

81. Wippel K, Tao K, Niu Y, Zgadzaj R, Kiel N, Guan R, et al. Host preference and invasiveness of commensal bacteria in the lotus and Arabidopsis root microbiota. Nat Microbiol. 2021;6(9):1150-62. https://doi.org/10.1038/s41564021-00941-9.

82. Ryan PR, Dessaux $Y$, Thomashow LS, Weller DM. Rhizosphere engineering and management for sustainable agriculture. Plant and Soil. 2009;321(1): 363-83. https://doi.org/10.1007/s11104-009-0001-6.

83. Lueders T, Manefield M, Friedrich MW. Enhanced sensitivity of DNA- and rRNA-based stable isotope probing by fractionation and quantitative analysis of isopycnic centrifugation gradients. Environ Microbiol. 2004;6(1): 73-8. https://doi.org/10.1046/j.1462-2920.2003.00536.x.

84. Dowd SE, Callaway TR, Wolcott RD, Sun Y, McKeehan T, Hagevoort RG, et al. Evaluation of the bacterial diversity in the feces of cattle using $16 \mathrm{~S}$ rDNA bacterial tag-encoded FLX amplicon pyrosequencing (bTEFAP). BMC Microbiol. 2008;8(1):125. https://doi.org/10.1186/1471-2180-8-125.

85. Dowd SE, Wolcott RD, Sun Y, McKeehan T, Smith E, Rhoads D. Polymicrobial nature of chronic diabetic foot ulcer biofilm infections determined using bacterial tag encoded FLX amplicon pyrosequencing (bTEFAP). PLoS One. 2008;3(10):e3326. https://doi.org/10.1371/journal.pone.0003326.

86. DeSantis TZ, Hugenholtz P, Larsen N, Rojas M, Brodie EL, Keller K, et al, Greengenes, a chimera-checked 165 rRNA gene database and workbench compatible with ARB. Appl Environ Microbiol. 2006;72(7):5069-72. https:// doi.org/10.1128/AEM.03006-05.

87. R Core Team. R: a language and environment for statistical computing. $R$ Foundation for Statistical Computing, Vienna, Austria. https://www.R-project. org/. 2017.

88. PRJEB32900- RNA stable isotope probing in A. echinatior ants. European Nucleotide Archive. https://www.ebi.ac.uk/ena/browser/view/PRJEB32900. 2019.

89. Westermann AJ, Forstner KU, Amman F, Barquist L, Chao Y, Schulte LN, et al. Dual RNA-seq unveils noncoding RNA functions in host-pathogen interactions. Nature. 2016;529(7587):496-501. https://doi.org/10.1038/nature1 6547.
90. PRJEB32903- Dual RNA sequencing of A. echinatior leafcutter ant laterocervical plates to establish secondary metabolite production by Pseudonocardia symbionts in vivo. 2019. https://www.ebi.ac.uk/ena/ browser/view/PRJEB32903

91. Kim D, Langmead B, Salzberg SL. HISAT: a fast spliced aligner with low memory requirements. Nat Methods. 2015;12(4):357-60. https://doi.org/10.1 038/nmeth.3317.

92. Anders S, Pyl PT, Huber W. HTSeq- a Python framework to work with highthroughput sequencing data. Bioinformatics. 2015;31(2):166-9. https://doi. org/10.1093/bioinformatics/btu638.

93. Mortazavi A, Williams BA, McCue K, Schaeffer L, Wold B. Mapping and quantifying mammalian transcriptomes by RNA-Seq. Nat Methods. 2008;5(7): 621-8. https://doi.org/10.1038/nmeth.1226.

94. Kanehisa M, Sato Y, Morishima K. BlastKOALA and GhostKOALA: KEGG tools for functional characterization of genome and metagenome sequences. J Mol Biol. 2016;428(4):726-31. https://doi.org/10.1016/j.jmb.2015.11.006.

95. Blin K, Wolf T, Chevrette MG, Lu X, Schwalen CJ, Kautsar SA, et al. antiSMASH 4.0-improvements in chemistry prediction and gene cluster boundary identification. Nucleic Acids Res. 2017;45(W1):W36-41. https://doi. org/10.1093/nar/gkx319.

96. Kieser T, Bibb MJ, Buttner MJ, Chater KF, Hopwood DA. Practical Streptomyces genetics. Norwich: John Innes Foundation; 2000.

97. Rueden CT, Schindelin J, Hiner MC, DeZonia BE, Walter AE, Arena ET, et al. ImageJ2: ImageJ for the next generation of scientific image data. BMC Bioinformatics. 2017;18(1):529. https://doi.org/10.1186/s12859-017-1934-z.

98. Schindelin J, Arganda-Carreras I, Frise E, Kaynig V, Longair M, Pietzsch T, et al. Fiji: an open-source platform for biological-image analysis. Nat Methods. 2012;9(7):676-82. https://doi.org/10.1038/nmeth.2019.

99. Worsley SF, Innocent TM, Holmes NA, M. A-BM, Wilkinson B, Murrell JC, et al. Competition-based screening secures the evolutionary stability of a defensive microbiome. GitHub Repository. 2021. https://github.com/ dougwyu/Worsley_et_al_screening_test_R_code.

100. Bates D, Mächler M, Bolker B, Walker S. Fitting linear mixed-effects models using Ime4. J Stat Softw. 2015;67(1):1-48.

\section{Publisher's Note}

Springer Nature remains neutral with regard to jurisdictional claims in published maps and institutional affiliations.

Ready to submit your research? Choose BMC and benefit from

- fast, convenient online submission

- thorough peer review by experienced researchers in your field

- rapid publication on acceptance

- support for research data, including large and complex data types

- gold Open Access which fosters wider collaboration and increased citations

- maximum visibility for your research: over $100 \mathrm{M}$ website views per year

At BMC, research is always in progress.

Learn more biomedcentral.com/submissions 